Article

\title{
Optimal Operation of Conventional Power Generation with High Penetration of Renewable Energy using Equilibrium Optimizer Technique
}

\author{
Khaled Nusair ${ }^{1}$ and Lina Alhmoud ${ }^{2, *}$ \\ 1 Protection and Metering Department, National Electric Power Company, Amman 11181,Jordan; \\ khalednusair2016@yahoo.com \\ 2 Department of Power Engineering, Hijjawi Faculty for Engineering Technology, Yarmouk University, Irbid \\ 21163,Jordan;lina.hmoud@yu.edu.jo \\ * Correspondence: lina.hmoud@yu.edu.jo
}

\begin{abstract}
Over the last decades, the energy market around the world has reshaped due to accommodating the high penetration of renewable energy resources. Although renewable energy sources have brought various benefits, including low operation cost of wind and solar PV power plants, and reducing the environmental risks associated with the conventional power resources, they have imposed a wide range of difficulties in power system planning and operation. Naturally, classical optimal power flow (OPF) is a nonlinear problem. Integrating renewable energy resources with conventional thermal power generators escalates the difficulty of the OPF problem due to the uncertain and intermittent nature of these resources. To address the complexity associated with the process of the integration of renewable energy resources into the classical electric power systems, two probability distribution functions (Weibull and lognormal) are used to forecast the voltaic power output of wind and solar photovoltaic, respectively. Optimal power flow, including renewable energy, is formulated as a single-objective and multi-objective problem in which many objective functions are considered, such as minimizing the fuel cost, emission, real power loss, and voltage deviation. Real power generation, bus voltage, load tap changers ratios, and shunt compensators values are optimized under various power systems' constraints. This paper aims to solve the OPF problem and examines the effect of renewable energy resources on the above-mentioned objective functions. A combined model of wind integrated IEEE 30-bus system, solar PV integrated IEEE 30-bus system, and hybrid wind and solar PV integrated IEEE 30-bus system are performed using the equilibrium optimizer technique (EO) and other five heuristic search methods. A comparison of simulation and statistical results of EO with other optimization techniques showed that EO is more effective and superior.
\end{abstract}

Keywords: Active power loss; total generation cost; emission index; optimal power flow; equilibrium optimizer; solar PV integrated IEEE 30-bus system; wind integrated IEEE 30-bus system; hybrid wind and solar PV integrated IEEE 30-bus system

\section{Introduction}

\subsection{Background}

The urgent need for reducing the fuel cost of the conventional power generation units and minimizing the greenhouse gases emitted from the thermal power generators have led various electric power companies to go toward utilizing renewable energy resources. Furthermore, advanced technologies of renewable energy resources have contributed significantly to be the most inexpensive and environmentally friendly. Integrating wind and solar PV in proper locations and appropriate settings of the variables of the conventional power networks may have a significant impact on the performance of power system control and operation. 
To make the modeling of wind and solar PV more accurate and realistic, the Weibull probability distribution function was used to forecast the wind speed [1]-[2]. Whereas lognormal probability distribution function is used to mimic the intermittent nature of solar irradiance in [3] [4].

\subsection{Literature review}

Numerous publications in the literature studied the optimal power flow (OPF) problem for systems consisting of conventional power generation and renewable-energy power plants. Deterministic, stochastic or hybrid optimization methods are used extensively to address the issues associated with increased penetration of non-dispatchable renewable energy, advanced controls such as FACTs devices and deregulated electricity markets.

Various conventional optimization techniques are used to solve the OPF problem. For instance, continuous nonlinear programming was proposed [5]. An extended conic quadratic format [6] is presented to solve the economic dispatch and decrease real power loss. Besides, the predictor-corrector interior point algorithm is proposed to fit the OPF for solving nonlinear programming problems [7]. Quadratic programming is used to derive a loss formula based on the incremental power flow [8]. Sequential quadratic programming is used to address large scale OPF; it also depends on transforming the original problem to a sequence of linearly constrained sub-problem by applying an augmented lagrangian [9]. Mixed-integer linear programming to minimize transmission losses and reactive generator outputs are adapted [10]. Although these methods have excellent convergence characteristics, they have various drawbacks, including failing to find the global solution because of non-convexity and facing difficulty while handling the problems with non-differentiable and discontinuous objective functions.

Recently, metaheuristic optimization algorithms have been gaining much attention due to flexibility, free of derivation, and local optima avoidance. Thus, single and multi-objective optimization methods overcome the shortcomings attributed to classical techniques. A gravitational search algorithm to find the optimal solution for OPF and IEEE 30-bus and 57-bus systems are examined [11]. The basic fuel cost, voltage profile, voltage stability, and non-smooth quadratic cost are minimized and optimized using a differential evolution algorithm [12]. The Black hole-based optimization method is used to address the OPF problem for IEEE 30-bus and Algerian 59-bus power systems [13]. Constrained OPF problem for IEEE 30-bus, 57-bus, and 118-bus is optimized using a moth swarm algorithm [14]. A multi-objective OPF to minimize the generation cost and environmental pollution using a fuzzy membership function to choose a compromise solution from the Pareto optimal solutions is discussed [15]. The fuel cost, voltage deviation, and real power loss are minimized as a multi-objective OPF problem using a gravitational search algorithm [16]. A modified teaching learning-based optimization algorithm added a self-adapting wavelet mutation strategy and a fuzzy clustering [17]. A hybrid of fuzzy evolutionary and swarm optimization is proposed to minimize the cost of active power generation and real power losses [18].

A fuzzy-based modified bee colony is presented to solve discrete OPF using multi-objective mixed integer nonlinear [19]. Emission, real power losses, and voltage deviation are all minimized as a multi-objective OPF using a multi-objective modified imperialist competitive algorithm [20]. The particle swarm optimization and the shuffled frog leaping algorithm are hybridized to solve OPF using the generator's constraints such as prohibited zones and valve point effect [21]. A chaotic invasive weed optimization algorithm is proposed to solve the OPF problem with non-smooth and non-convex fuel cost curves [22]. Brainstorming optimization and teaching-learning optimization are hybridized to minimize the fuel cost of thermal generation units [23]. A hybrid optimization algorithm is based on sequential quadratic programming to generate an initial population. Then a differential evolution took that population to find the optimal solution more effectively and it was used to minimize the fuel cost with valve point and the transmission line real losses [24].

A growing and considerable effort have been made in recent years to solve and model the OPF problem, including renewable energy sources. The OPF problem with taking into account uncertainties in the wind, solar, and load forecast and optimized using a genetic algorithm and two-point estimate method [25]. A hybrid method called moth swarm algorithm and gravitational search algorithm is used to solve the problem of OPF, including wind power [26]. A modified two-point estimation method is used to solve probabilistic OPF incorporating wind and solar photovoltaic [27]. Hybrid wind photovoltaic power systems are optimized using the unscented transformation method, which can carry out probabilistic OPF with high accuracy and less computational time 
[28]. The OPF, including wind is optimized using a fuzzy-based particle swarm optimization. A fuzzy set modeled the forecast load demand and wind speed [29].

Besides, OPF incorporating wind power energy is optimized by a hybrid algorithm called a hybrid dragonfly with aging particle swarm optimization [30]. Adaptive differential evolution with proper constraint handling method is addressed OPF, including wind and solar. The forecast wind and solar photovoltaic are modeled using Weibull and lognormal probability distribution functions [31]. An optimal reactive power dispatch with solar photovoltaic power and its impact on minimizing real power losses is addressed using the Jaya algorithm to solve this issue [32]. A constrained multi-objective population external optimization method in [33] is presented to minimize the fuel cost and emission in the presence of renewable energy sources. A grey wolf optimization algorithm in [34] was proposed to tune the parameters of a thyristor controlled series compensator and address OPF, including wind and solar power. A gbest guided artificial bee colony optimization in [1] was to find the optimal setting of conventional and renewable power generation.

\subsection{Contribution and paper organization}

In the present work, an equilibrium optimizer [35], which is a novel optimization method inspired by controlling the volume mass balance model for estimating both equilibrium and dynamic states, is used to prove its performance in solving the OPF problem. It is implemented on i) IEEE 30-bus system, ii) wind integrated IEEE 30-bus system, iii) solar PV integrated IEEE 30-bus system, and iv) hybrid wind and solar PV integrated IEEE 30-bus system. Real power loss minimizations, total cost minimization of generating units and emission index minimization are considered to be the objective functions of the OPF problem. Weibull and lognormal probability distribution functions are used to model the wind speed and solar irradiance to forecast the output power of wind and solar PV systems. Furthermore, aiming to fill the gap in the literature, this paper investigates the impact of the presence of only wind or only solar PV or both of them on enhancing the objective functions of the OPF problem. In addition, a comprehensive statistical analysis for the equilibrium optimizer technique (EO) and other optimization techniques are analysed.

The rest of this paper is organized as follows: the formulation of OPF problem is described in Section 2. Then, a mathematical models of wind and solar PV plants are introduced in Section 3. Section 4 presents the equilibrium optimizer technique (EO) and its implementation to solve the OPF problem. Simulation results are explained in Section 6. Finally, Section 7 draws the conclusion of this work.

\section{Problem formulation of OPF}

\subsection{General structure of $O P F$}

Generally, OPF aims to minimizes some objective functions. $f_{o}$ is the objective function to be minimized , and $h$ and $g$ are the equality and inequality constraints in the power system network, OPF can be expressed as $[14,36]$ :

$$
\begin{array}{ll}
\text { Minimize } & f_{o}(x, u) \\
\text { Subject to } & g(x, u) \leq 0 \\
& h(x, u)=0
\end{array}
$$

$x$ is a state vector of dependent variables including real power of swing generator $\left(P_{G_{1}}\right),\left(V_{L_{i}}\right)$ is the voltage magnitude of load buses, $\left(Q_{G_{i}}\right)$ is the reactive power of generator at $i_{t h}$ bus and $\left(S_{l_{i}}\right)$ is the loading of the $i_{t h}$ transmission line. $x$ can be expressed as follows [14,36]:

$$
x=\left[P_{G_{1}}, V_{L_{1}}, \ldots, V_{L_{n p q}}, Q_{G 1}, \ldots, Q_{G_{N G}}, S_{l_{1}}, \ldots, S_{l_{n_{l}}}\right]^{T}
$$

where $n p q$, and $n_{l}$ are the number of PQ buses and transmission lines. $S_{l}$ and $n_{l}$ are loading of transmission lines and the number of transmission lines, respectively. 
$u$ is a vector consisting of control variables, $\left(P_{G_{i}}\right)$ is the real power of all generators excluding swing generator, $\left(V_{G_{i}}\right)$ is the voltage magnitude of generators, $(T S)$ is the branch transformer tap, and $\left(Q_{C}\right)$ is the shunt capacitors. $u$ can be expressed as follows [14,36]:

$$
u=\left[P_{G_{2}}, \ldots, P_{G_{N G}}, V_{G_{1}}, \ldots, V_{G_{N G}}, Q_{C 1}, \ldots, Q_{C N_{c}}, T S_{1}, \ldots, T S_{N_{T}}\right]^{T}
$$

where, $N G, N_{c}$ and $N_{T}$ are the number of generators, shunt VAR compensator and transformers, respectively.

\subsection{Objective functions of $O P F$}

Here, the first four cases dealt with solving single objective OPF and the last one addressed the multi-objective OPF.

- Case 1: real power loss minimization

Due to the presence of the inherent resistance for the transmission lines, the aim of this function is to minimize the active power losses and it is expressed as [14,36]:

$$
f_{o}(x, u)=P_{l o s s}=\sum_{q=1}^{n l} G_{q_{(i j)}}\left(V_{i}^{2}+V_{j}^{2}-2 V_{i} V_{j} \cos \left(\delta_{i j}\right)\right)
$$

Where $G_{q(i j)}$ is the conductance of $q_{t h}$ transmission line, and $V_{i}$ and $V_{j}$ are the voltage magnitude of terminal buses of transmission line.

- Case 2: emission index minimization

In the present case, the target is to reduce the harmful gases emission from the thermal generation units, and the coefficients of the gas emission of the thermal power generators are given in Table 1. Emission in tons per hour $(\mathrm{t} / \mathrm{h})$ can be described by $[14,36]$ :

$$
f_{o}(x, u)=E=\sum_{i=1}^{N G}\left[\left(\alpha_{i}+\beta_{i} P_{G_{i}}+\gamma_{i} P_{G_{i}}^{2}\right) * 0.01+\omega_{i} e^{\left(\mu i P_{G_{i}}\right)}\right]
$$

where $\alpha, \beta, \gamma, \omega$ and $\mu$ are the emission coefficient and they are given in Table 1 .

Table 1. Emission coefficients of thermal power generating units.

\begin{tabular}{lllllll}
\hline Generator & Bus & $\alpha$ & $\beta$ & $\gamma$ & $\omega$ & $\mu$ \\
\hline G1 & 1 & 4.091 & -5.554 & 6.49 & 0.0002 & 2.857 \\
G2 & 2 & 2.543 & -6.047 & 5.638 & 0.0005 & 3.333 \\
G3 & 5 & 4.258 & -5.094 & 4.586 & 0.000001 & 8 \\
G4 & 8 & 5.326 & -3.55 & 3.38 & 0.002 & 2 \\
G5 & 11 & 4.258 & -5.094 & 4.586 & 0.000001 & 8 \\
G6 & 13 & 6.131 & -5.555 & 5.151 & 0.00001 & 6.667 \\
\hline
\end{tabular}

- Case 3: Basic fuel cost minimization

The relationship between fuel cost $(\$ / h)$ and the power generated from the thermal generating units can be approximately given by the quadratic relationship and it is expressed as [14,36]:

$$
f_{o}(x, u)=F C=\sum_{i=1}^{N G} a_{i}+b_{i} P_{G_{i}}+c_{i} P_{G_{i}}^{2}
$$

where $a_{i}, b_{i}, c_{i}$ are the cost coefficient of the thermal generators and these coefficients are provided in Table 2. 
Table 2. Cost coefficients of the thermal power generators.

\begin{tabular}{lllll}
\hline Generator & Bus & $\mathrm{a}$ & $\mathrm{b}$ & $\mathrm{c}$ \\
\hline G1 & 1 & 0 & 2 & 0.00375 \\
G2 & 2 & 0 & 1.75 & 0.0175 \\
G3 & 5 & 0 & 1 & 0.0625 \\
G4 & 8 & 0 & 3.25 & 0.00834 \\
G5 & 11 & 0 & 3 & 0.025 \\
G6 & 13 & 0 & 3 & 0.025 \\
\hline
\end{tabular}

- Case 4: Voltage deviation minimization

The voltage deviation index is the cumulative deviation of all load buses from nominal value of unity. It also play a significant role in keeping the voltage quality and security of the electrical power network.This case is expressed as [14,36]:

$$
f_{o}(x, u)=V D=\left(\sum_{p=1}^{N L}\left|V_{L_{p}}-1\right|\right)
$$

- Case 5: Minimization of basic the fuel cost, emission index,voltage deviation and the real power losses. The aim of this case is to reduce quadratic fuel cost, active power transmission losses, environmental emission index and voltage deviation index simultaneously. It can be defined as follows[14,36]:

$$
f_{o}(x, u)=\sum_{i=1}^{N G} a_{i}+b_{i} P_{G_{i}}+c_{i} P_{G_{i}}^{2}+\lambda_{p} \times P_{l o s s}+\lambda_{V D} \times V D+\lambda_{E} \times E
$$

where $\lambda_{p}, \lambda_{V D}$ and $\lambda_{E}$ are weight factors and they are assumed to be 22, 21 and 19, respectively as in [14].

\subsection{Constraints}

The constraints of OPF are usually categorized into [14,36]:

1. Equality constraints

The equality constraints of OPF are usually represented by the load flow equations:

$$
\begin{gathered}
P_{G_{i}}-P_{D_{i}}=V_{i} \sum_{k=1}^{N_{B}} V_{k}\left(G_{i k} \cos \theta_{i k}+B_{i k} \sin \theta_{i k}\right) \\
Q_{G_{i}}-Q_{D_{i}}=V_{i} \sum_{k=1}^{N_{B}} V_{k}\left(G_{i k} \sin \theta_{i k}-B_{i k} \cos \theta_{i k}\right)
\end{gathered}
$$

where $P_{D_{i}}, Q_{D_{i}}, N_{B}$, and $\theta_{i k}$ are the active and reactive load demand,the reactive load demand, the number of buses and the angle difference between bus $\mathrm{i}$ and k, respectively. $G_{i k}$ and $B_{i k}$ are the transfer and susceptance conductance.

2. Inequality constraints

It can be defined by operating limits on the equipment of the power system, transmission loading and voltage of load buses.

(a) Constraints of thermal and renewable energy generating units

$$
\begin{aligned}
V_{G_{i, \text { min }}} & \leq V_{G_{i}} \leq V_{G_{i, \max }} i=1, \ldots, N \\
P_{G_{i, \min }} & \leq P_{G_{i}} \leq P_{G_{i, \max }} i=1, \ldots, N \\
Q_{G_{i, \text { min }}} & \leq Q_{G_{i}} \leq Q_{G_{i, \max }} i=1, \ldots, N
\end{aligned}
$$

(b) Constraints of the transformer tap setting

$$
T S_{k, \min } \leq T S_{k} \leq T S_{k, \max } k=1, \ldots, N_{T}
$$


(c) constraints of the shunt compensator

$$
Q_{C, j, \min } \leq Q_{C} \leq Q_{C, j, \max } j=1, \ldots, N_{C}
$$

(d) Constraints of the voltages at load buses

$$
V_{L r, \min } \leq V_{L r} \leq V_{L r, \max } r=1, \ldots, N_{L}
$$

(e) Constraints of the transmission line loading

$$
S_{l v} \leq S_{l v, \text { max }} v=1, \ldots, n_{l}
$$

\subsection{Constraint handling}

In order to decline the infeasible solutions of OPF and keep the dependent variables within the allowable ranges, a penalty function was modeled and added to the objective functions defined in Section 2.2 [14,36].

$$
\text { penalty }=K_{p}\left(P_{G 1}-P_{G 1}^{L i m}\right)^{2}+K_{Q} \sum_{i=1}^{N G}\left(Q_{G i}-Q_{G i}^{L i m}\right)^{2}+K_{V} \sum_{i=1}^{N L}\left(V_{L i}-V_{L i}^{L i m}\right)^{2}+K_{S} \sum_{i=1}^{n l}\left(S_{l i}-S_{L i}^{L i m}\right)^{2}
$$

where $K_{Q}, K_{p}, K_{V}$ and $K_{S}$ are the values of penalty factors associated with generation reactive power, generation real power of the swing generator, load bus voltages and line flow of transmission lines. They are assumed to be $100,100,100$, and 100,000, respectively [14,37], and $x^{\text {Lim }}$ is the value of the violated limit of dependent variables $(x)$. It is equal to $x^{\max }$ in case of $x>x^{\max }$ or $x^{\min }$ in case of $x<x^{\min }$.

\section{Mathematical models of the wind \& solar power generating units}

\subsection{Wind power units}

\subsubsection{Uncertain and power model of wind turbines}

The wind speed of the wind turbines follows the Weibull probability distribution function. The characteristic of the output power generated by the wind turbine is a random variable depending on wind speed. The Weibull probability distribution function with dimensionless shape factor $(k)$ and scale factor $(c)$ is used to model the wind speed $f_{(v)}(v)$. The wind speed $\left(f_{(v)}(v)\right)$ can be expressed mathematically as $[1,2,38,39]$ :

$$
f_{v}(v)=\frac{k}{c}\left(\frac{v}{c}\right)^{k-1} \times e^{-\left(\frac{v}{c}\right)^{k}}
$$

Mean of Weibull distribution $\left(M_{w b l}\right)$ can be expressed as [31,40-42]:

$$
M_{w b l}=c * \Gamma\left(1+K^{-1}\right)
$$

The electrical energy generated by a wind turbine $\left(P_{w}(v)\right)$ is the result of converting of the kinetic energy of wind and it can be estimated as [1,2,38,39]:

$$
P_{w}(v)= \begin{cases}0 & v<v_{\text {in }} \text { and } v>v_{\text {out }} \\ P_{w r}\left(\frac{v-v_{\text {in }}}{v_{r}-v_{\text {in }}}\right) & v_{\text {in }} \leq v \leq v_{r} \\ P_{w r} & v_{r}<v \leq v_{\text {out }}\end{cases}
$$

where $\left(P_{w t}\right),\left(v_{\text {in }}\right),\left(v_{\text {out }}\right)$ and $\left(v_{r}\right)$ are the rated power of the wind turbine, the cut-in wind speed of the wind turbine, the cut-out wind speed and the rated wind speed, respectively. 
3.1.2. Calculation of direct, underestimation and overestimation cost of wind power

The direct cost of wind power plant can be defined as[31,40-42]:

$$
C_{w, j}\left(P_{w s, j}\right)=g_{j} P_{w s, j}
$$

where $g_{j}$ is the direct cost coefficient of wind plant. The cost function is overestimated because the actual generated power from the wind turbine is less than the estimated power by mathematical equations. The overestimation cost is used for reverse the requirements when the estimated output power of the wind turbine is more than actual output power. Reserve cost for the $j^{\text {th }}$ wind turbine can be defined as [31,40-42]:

$$
\begin{gathered}
C_{R w, j}\left(P_{w s, j}-P_{w a v, j}\right)=K_{R w, j}\left(P_{w s, j}-P_{w a v, j}\right) \\
=K_{R w, j} \int_{0}^{P_{w s, j}}\left(P_{w s, j}-P_{w, j}\right) f_{w}\left(P_{w, j}\right) d P_{w, j}
\end{gathered}
$$

where $K_{R w, j}, P_{w a v, j}, P_{w s, j}$ and $f_{w(p w, j)}$ are the reserve cost coefficient pertaining to $j^{t h}$ wind turbine, the actual available power from the same plant, the estimated power from the $j^{\text {th }}$ wind turbine and the wind power probability density function for $j^{t h}$ wind turbine. Underestimation cost function of the wind turbine is due to not using the whole power which is generated from the wind turbine. In other words, when the generated power from the wind turbine is more than the estimated power, underestimation cost function is applied as a penalty due to waste the surplus power. The Penalty cost for the $j^{\text {th }}$ wind turbine can be defined as $[31,40-42]$ :

$$
\begin{array}{r}
C_{P w, j}\left(P_{w a v, j}-P_{w s, j}\right)=K_{P w, j}\left(P_{w a v, j}-P_{w s, j}\right) \\
=K_{P w, d} \int_{P_{w s, j}}^{P_{w r, j}}\left(P_{w, j}-P_{w s, j}\right) f_{w}\left(P_{w, j}\right) d P_{w, j}
\end{array}
$$

where $K_{P w, j}$ is a coefficient represent the penalty cost for the $j^{\text {th }}$ wind turbine and $P_{w r, j}$ is the rated output power which is generated from the $j^{\text {th }}$ wind turbine. As shown in Section 3.1.2, the total cost of wind power turbines $\left(C_{T}^{W}\right)$ can be described as follows:

$$
C_{T}^{W}=\sum_{j=1}^{N_{w}} C_{w, j}\left(P_{w s, j}\right)+C_{R w, j}\left(P_{w s, j}-P_{w a v, j}\right)+C_{P w, j}\left(P_{w a v, j}-P_{w s, j}\right)
$$

where $N_{w}$ is the number of wind power turbines.

\subsection{Solar power units}

\subsubsection{Uncertain and power model of solar PV plants}

Solar irradiance can be modelled by Lognormal probability distribution function due to its uncertain and stochastic nature. The Lognormal probability distribution is a function of solar irradiance (G) with mean $\mu$ and standard deviation $\sigma$, it can be expressed mathematically as [3], and [4]:

$$
f_{G}(G)=\frac{1}{G \sigma \sqrt{2 \pi}} \exp \left(\frac{-(\ln x-\mu)^{2}}{2 \sigma^{2}}\right) G>0
$$

Mean of lognormal distribution $M_{l g n}$ can be expressed as:

$$
M_{l g n}=\exp \left(\mu+\frac{\sigma^{2}}{2}\right)
$$


The main role of PV systems is to convert the solar irradiance to electrical energy. The output power of PV system $\left(P_{S}(G)\right)$ as a function of irradiance can be estimated as [31,40]:

$$
P_{s}(G)= \begin{cases}P_{s r} \frac{G^{2}}{G_{s t d} R_{c}} & \text { for } 0<G<R_{c} \\ P_{s r} \frac{G}{G_{s t d}} & \text { for } G \geq R_{c}\end{cases}
$$

where $G_{s t d}$ represents the solar irradiance in standard environment, $R_{c}$ is a certain irradiance point, and $P_{s r}$ is the rated output power which is generated from the solar PV system.

\subsubsection{Calculation of direct, underestimation, and overestimation cost of solar PV power}

The direct cost of solar power plant can be defined as $[31,40]$ :

$$
C_{s, k}\left(P_{s s, k}\right)=h_{k} P_{s s, k}
$$

where $h_{k}$ is a coefficient represents the direct cost of solar photovoltaic plant.

The same case as in wind energy system, solar energy system in involves overestimation and underestimation cost due its uncertain output power. Reserve cost for the overestimation of $k^{\text {th }}$ solar PV system is $[31,40]$ :

$$
\begin{array}{r}
C_{R s, k}\left(P_{s s, k}-P_{s a v, k}\right)=K_{R s, k}\left(P_{s s, k}-P_{s a v, k}\right) \\
=K_{R s, k} * f_{s}\left(P_{s a v, k}<P_{s s, k}\right) * \\
{\left[P_{s s, k}-E\left(P_{s a v, k}<P_{s s, k}\right)\right]}
\end{array}
$$

where $K_{R s, k}$ is a coefficient represents the reserve cost pertaining to $k^{\text {th }}$ solar PV system, $P_{s a v, k}$ is the actual available power from the same plant, $f_{s}\left(P_{s a v}, k<P_{s s, k}\right)$ is the probability of solar power shortage occurrence than the scheduled power $\left(P_{s s, k}\right)$ and $E\left(P_{s a v, k}<P_{s s, k}\right)$ is the expectation of solar PV power below $P_{s s, k}$. In case of the underestimation of $k^{\text {th }}$ solar PV system, the penalty cost is given as [31,40]:

$$
\begin{array}{r}
C_{P s, k}\left(P_{s a v, k}-P_{s s, k}\right)=K_{P s, k}\left(P_{s a v, k}-P_{s s, k}\right) \\
=K_{P s, k} * f_{s}\left(P_{s a v, k}>P_{s s, k}\right) * \\
{\left[E\left(P_{s a v, k}>P_{s s, k}\right)-P_{s s, k}\right]}
\end{array}
$$

where $K_{P s, k}$ is a coefficient represents the penalty cost pertaining to $k^{\text {th }}$ solar PV system, $f_{s}\left(P_{s a v, k}<P_{s s, k}\right)$ is the probability of solar power surplus than the scheduled power $\left(P_{s s, k}\right)$ and $E\left(P_{s a v, k}<P_{s s, k}\right)$ is the expectation of solar PV power above $P_{s s, k}$. As explained in Section 3.2.2, the total cost of solar PV plants $\left(C_{T}^{P V}\right)$ consists of three terms(direct, underestimation and overestimation cost) and it can be given as follow [31,40]:

$$
C_{T}^{P V}=\sum_{k=1}^{N_{P V}} C_{s, k}\left(P_{s s, k}\right)+C_{P s, k}\left(P_{s a v, k}-P_{s s, k}\right)+C_{R s, k}\left(P_{s s, k}-P_{s a v, k}\right)
$$

where $N_{P V}$ is the number of the solar PV plants.

\section{Proposed EO}

\subsection{Inspiration and mathematical model}

The main inspiration for this algorithm is the dynamic mass balance equation which describes the conservation of mass which enters, leaves or generates in a control volume. This equation is a first-order ordinary differential equation and it is described as following [35]:

$$
V \frac{d C}{d t}=Q C_{e q}-Q C+G
$$


where $V \frac{d C}{d t}$ is the rate of change of mass in volume, $(V), C$ is the concentration inside the volume $(V), V$ is the control volume, $Q$ is the volumetric flow rate into and out of the control volume, $C_{e q}$ is the concentration at an equilibrium state.

After reaching the steady equilibrium state of equation (33) that is reformulated as a function of $\left(\frac{Q}{V}\right)$ which is called turnover rate $\left(\lambda=\frac{Q}{V}\right)$. The following equations are derived from equation (33) to solve for (C) as a function of time $(t)[35]$ :

$$
\begin{gathered}
\frac{d C}{\lambda C_{e q}-\lambda C+\frac{G}{V}}=d t \\
\int_{C_{0}}^{C} \frac{d C}{\lambda C_{e q}-\lambda C+\frac{G}{V}}=\int_{t_{0}}^{t} d t \\
F=e^{-\lambda\left(t-t_{0}\right)} \\
C=C_{e q}+\left(C_{0}-C_{e q}\right) F+\frac{G}{\lambda V}(1-F)
\end{gathered}
$$

where $F, t_{0}$ is the initial start time and $C_{0}$ is the initial concentration.

The equation (37) introduces three rules for updating the concentration of each particle. The equilibrium concentration is the first term which is described as one of the best-so-far solutions randomly chosen from the equilibrium pool. The difference between a concentration of a particle and the equilibrium state is the second term which helps particles to globally explore the domain. The final term is called the generation rate which mainly acts as an exploiter or solution refiner [35].

\subsection{The interaction between each term and the search pattern and the definition of the EO's terms}

\subsubsection{Initialization and function evaluation}

Firstly, the optimization process starts with the initial population. The equation (38) describes the initial concentration process which depends on the number of particles and dimensions that initialized in the search space in a uniform random manner [35].

$$
C_{i}^{\text {initial }}=C_{\text {min }}+\operatorname{rand}_{i}\left(C_{\max }-C_{\text {min }}\right)
$$

where $C_{i}^{\text {initial }}$ is the initial concentration vector of the ith particle, $C_{\min }$ is the minimum value for the dimensions, $C_{\text {max }}$ is the maximum value for the dimensions and rand $_{i}$ is a random vector ranges between zero and one. After that, the fitness function of the particles are evaluated and then solved to determine the equilibrium conditions.

\subsubsection{Equilibrium pool and candidates $\left(C_{e q}\right)$}

The global optimum of EO is represented by the equilibrium state. At the beginning, no information about the equilibrium state is existed, but equilibrium candidates are identified to provide a search domain for the particles. There are five equilibrium candidates as given in equation 39. Four of them are the best-so-far particles determined during the optimization process and the last one is the arithmetic mean of the previous-mentioned four particles. The main goal of the first four candidates is to improve the exploration capability, whereas the fifth candidate enhances the exploitation [35]

$$
\begin{gathered}
C_{a v g}=\vec{C}_{e q}(1)+\vec{C}_{e q}(2)+\vec{C}_{e q}(3)+\vec{C}_{e q}(4) \\
C_{e q, p o o l}=\left\{\vec{C}_{e q}(1), \vec{C}_{e q}(2), \vec{C}_{e q}(3), \vec{C}_{e q}(4), \vec{C}_{e q}(\text { ave })\right\}
\end{gathered}
$$




\subsubsection{Exponential term $(F)$}

The exponential term (F) helps EO to have an acceptable balance between exploration and exploitation. Referring back to equation (36), the time (t) in equation (36) depends on the iteration (Iter) and it is described as follows [35] :

$$
\left.t=\left(1-\frac{\text { Iter }}{\text { Max }}\right)^{\left(a_{2} \frac{\text { Iter }}{\text { Max }}\right.}\right)
$$

For the purpose of convergence, $t_{0}$ in equation (10) is proposed to slow down the search speed as well as enhancing the exploration and exploitation ability of EO [35].

$$
t_{0}=\frac{1}{\vec{\lambda}} \ln \left(-a_{1} \operatorname{sign}(\vec{r}-0.5)\left[1-e^{-\vec{\lambda} t}\right]\right)
$$

where $a_{1}$ and $a_{2}$ are constant values for controlling exploration and exploitation ability, $\operatorname{sign}(\vec{r}-0.5)$ is a factor that determine the direction of exploration and exploitation and $r$ is a random vector ranges between zero and one.

\subsubsection{The generation rate $(G)$}

The generation rate aims to provide the exact solution by enhancing the exploitation ability of EO and can be described as [35]:

$$
\vec{G}=\overrightarrow{G_{0}} e^{-\vec{k}\left(t-t_{0}\right)}
$$

After assumption that $k=\lambda$, the equation of generation rate was updated as follows [35]:

$$
\begin{gathered}
\vec{G}=\overrightarrow{G_{0}} \vec{F} \\
\overrightarrow{G_{0}}=\overrightarrow{G C P}\left(\overrightarrow{C_{e q}}-\vec{\lambda} \vec{C}\right) \\
\overrightarrow{G C P}= \begin{cases}0.5 r_{1}, & r_{2} \geq G P \\
0, & r_{2} \geq G P\end{cases}
\end{gathered}
$$

where $r_{1}$ and $r_{2}$ are random number between zero and one, GCP is the generation rate control parameter.

The generation rate control parameter (GCP) mainly depends on generation probability (GP) which defines the number of particles which uses generation term to update their states.

State of the art state that EO at $G P=0.5$, EO can achieve a good balance between exploration and exploitation. The updating rule of $\mathrm{EO}$ is given as:

$$
\vec{C}=\overrightarrow{C_{e q}}+\left(\vec{C}-\overrightarrow{C_{e q}}\right) \vec{F}+\frac{\vec{G}}{\vec{\lambda} V}(1-\vec{F})
$$

The second and third terms of equation (47) can increase variation and thus helps EO to better explore in case of they have same signs or to decrease the variation and aiding EO in local searches in case of having opposite signs [35].

\subsubsection{Particle's memory saving}

This can help each particle track with its coordinates in the space. It aids EO in exploitation capability and avoids getting trapped in local minima [35].

\section{Implementation of EO to solve the OPF problem}

The proposed EO is applied to solve OPF problem including wind and solar PV generation units. The following pseudo code explains the steps of the application of EO for OPF problem. 
1. Define the control and dependent variables and their limits as well as the target objective function defined in Section 2.2.

2. Collect and read the input data of the power system under test such as data of transmission lines, transformers, shunt VAR compensator, loads and generation units.

3. Calculate the estimated output power of solar PV and wind power generation units as defined and explained in Section 3.

4. Initialize the particle's populations.

5. Assign a large number to the fitness of equilibrium candidates and let a1=2; $a 2=1 ; \mathrm{GP}=0.5$.

6. Do the main while loop as following [35]:

(a) While (current iteration (Iter) <maximum number of iteration (Max-iter))

(b) For $\mathrm{i}=1$ : particles' number (n)

(c) Find the fitness value of the $i_{t h}$ particle

i. If fitness $\left(C_{i}\right)<$ fitness $\left(C_{e q 1}\right)$ then

Substitute $\left(C_{e q 1}\right)$ with $\left(C_{i}\right)$ and fitness $\left(C_{e q 1}\right)$

with fitness $\left(C_{i}\right)$

ii. Else if fitness $\left(C_{i}\right)>$ fitness $\left(C_{e q 1}\right) \&$ fitness $\left(C_{i}\right)<$ fitness $\left(C_{e q 2}\right)$ then

Substitute $\left(C_{e q 2}\right)$ with $\left(C_{i}\right)$ and fitness $\left(C_{e q 1}\right)$

with fitness $\left(C_{i}\right)$

iii. Else if fitness $\left(C_{i}\right)>$ fitness $\left(C_{e q 1}\right) \&$ fitness $\left(C_{i}\right)$

$>$ fitness $\left(C_{e q 2}\right) \&$ fitness $\left(C_{i}\right)<$ fitness $\left(C_{e q 3}\right)$ then

Substitute $\left(C_{e q 3}\right)$ with $\left(C_{i}\right)$ and fitness $\left(C_{e q 3}\right)$

with fitness $\left(C_{i}\right)$

iv. Else if fitness $\left(C_{i}\right)>$ fitness $\left(C_{e q 1}\right) \&$ fitness $\left(C_{i}\right)>$ fitness $\left(C_{e q 2}\right) \&$ fitness $\left(C_{i}\right)>$ fitness $\left(C_{e q 3}\right) \&$ fitness $\left(C_{i}\right)<$ fitness $\left(C_{e q 4}\right)$ then

Substitute $\left(C_{e q 4}\right)$ with $\left(C_{i}\right)$ and fitness $\left(C_{e q 4}\right)$ with fitness $\left(C_{i}\right)$

(d) End (if )

(e) $\operatorname{End}$ (for)

7. Find the $\overrightarrow{C_{\text {avg }}}$ according to equation (39).

8. Construct the equilibrium pool according to equation (40) [35].

9. In case of the current iteration $>1$, accomplish memory saving [35].

10. Assign $t$ according to equation (41).

11. Do the second for loop as following:

For $\mathrm{i}=1$ : particles' number

(a) Select one candidate from the equilibrium pool randomly.

(b) Create the two random vector ( $\lambda$ and $r$ ).

(c) Construct $F, G C P, G_{0}$ and $G$ according to the equation (36), equation (46), equation (45) and equation (44), respectively [35].

(d) Update the concentration $C$ according to equation (47)/

End the second for loop.

12. Increase the current iteration by one.

13. End the main while loop.

14. Extract and analysis of the results.

\section{Results and Discussion}

The performance and effectiveness of the EO is verified for solving OPF problem by carrying out 20 independent test trial runs for all cases discussed in Section 2.2. The EO [35] and other five metaheuristic optimization techniques: MFO [43], TACPSO [44], AGPSO1 [44], TLBO [45] and MPSO [44] have been tested on four power test systems given in Section 6.1. All these optimization techniques are implemented on $2.8-\mathrm{GHz}$ i7 PC with 16 GB of RAM using MATLAB 2017. 
The number of iteration, population size, testing ranges and other parameters of the optimization methods are given in Table 3.

Table 3. Control parameters values for optimization methods.

\begin{tabular}{|c|c|c|}
\hline Algorithm & Parameters & Values \\
\hline \multirow{5}{*}{ MPSO [44] } & Inertia coefficient $(\mathrm{w})$ & decreasing linearly from 0.9 to 0.4 \\
\hline & Number of search agents & 50 \\
\hline & Maximum number of iteration & 100 \\
\hline & Udapting factor $(\mathrm{C} 1, \mathrm{C} 2)$ & Descriped in [44] \\
\hline & Acceleration coefficient $(\mathrm{c} 1, \mathrm{c} 2)$ & $\mathrm{c} 1=1, \mathrm{c} 2=2$ \\
\hline \multirow{3}{*}{ TLBO [45] } & Teaching factor & Selected randomly $[1,2]$ \\
\hline & Population size & 50 \\
\hline & Maximum number of iteration & 100 \\
\hline \multirow{5}{*}{ TACPSO [44] } & Inertia coefficient $(\mathrm{w})$ & decreasing linearly from 0.9 to 0.4 \\
\hline & Number of search agents & 50 \\
\hline & Maximum number of iteration & 100 \\
\hline & Udapting factor $(\mathrm{C} 1, \mathrm{C} 2)$ & Descriped in [44] \\
\hline & Acceleration coefficient $(\mathrm{c} 1, \mathrm{c} 2)$ & $\mathrm{c} 1=1, \mathrm{c} 2=2$ \\
\hline \multirow{3}{*}{ MFO [43] } & Population size & 50 \\
\hline & Maximum number of iteration & 100 \\
\hline & Shape constant (b) & 1 \\
\hline \multirow{5}{*}{ AGPSO 1 [44] } & Inertia coefficient $(\mathrm{w})$ & decreasing linearly from 0.9 to 0.4 \\
\hline & Number of search agents & 50 \\
\hline & Maximum number of iteration & 100 \\
\hline & Udapting factor $(\mathrm{C} 1, \mathrm{C} 2)$ & Descriped in [44] \\
\hline & Acceleration coefficient $(\mathrm{c} 1, \mathrm{c} 2)$ & $\mathrm{c} 1=1, \mathrm{c} 2=2$ \\
\hline \multirow{5}{*}{ EO [35] } & Constant values for controlling exploration $\left(a_{1}\right)$ & 2 \\
\hline & Constant values for controlling exploitation $\left(a_{2}\right)$ & 1 \\
\hline & Number of search particles & 50 \\
\hline & Maximum number of iteration & 100 \\
\hline & Generation probability & 0.5 \\
\hline
\end{tabular}

\subsection{Description of the test power systems}

- Test system 1: IEEE 30-bus system

The IEEE 30-bus system consists of six thermal power generators, as presented in Figure 1.The data about transmission lines, tap changing transformers, AVR compensators, limitations on generators and load voltages, active and reactive power demand are given in [46-48]. The general specifications of this system are described in Table 4.

Table 4. The general specification of all test power systems.

\begin{tabular}{|c|c|c|c|c|}
\hline \multirow[b]{2}{*}{ Characteristics } & \multicolumn{4}{|c|}{ Values and Details } \\
\hline & Test system 1 [46-48] & Test system 2 & Test system 3 & Test system 4 \\
\hline Transmission Lines & 41 & 41 & 41 & 41 \\
\hline Limitation on load voltage & {$[0.95-1.1]$} & {$[0.95-1.1]$} & {$[0.95-1.1]$} & {$[0.95-1.1]$} \\
\hline Thermal power generators & 6 & 3 & 3 & 3 \\
\hline Wind power plants & 0 & 5 & 0 & 2 \\
\hline Shunt VAR compensation & 9 & 9 & 9 & 9 \\
\hline Transformer with tap ratio & 4 & 4 & 4 & 4 \\
\hline Control Variables & 24 & 28 & 28 & 28 \\
\hline Active and Reactive power demand & 283.4 MW ,126.2 Mvar & 283.4 MW ,126.2 Mvar & 283.4 MW ,126.2 Mvar & 283.4 MW ,126.2 Mvar \\
\hline
\end{tabular}




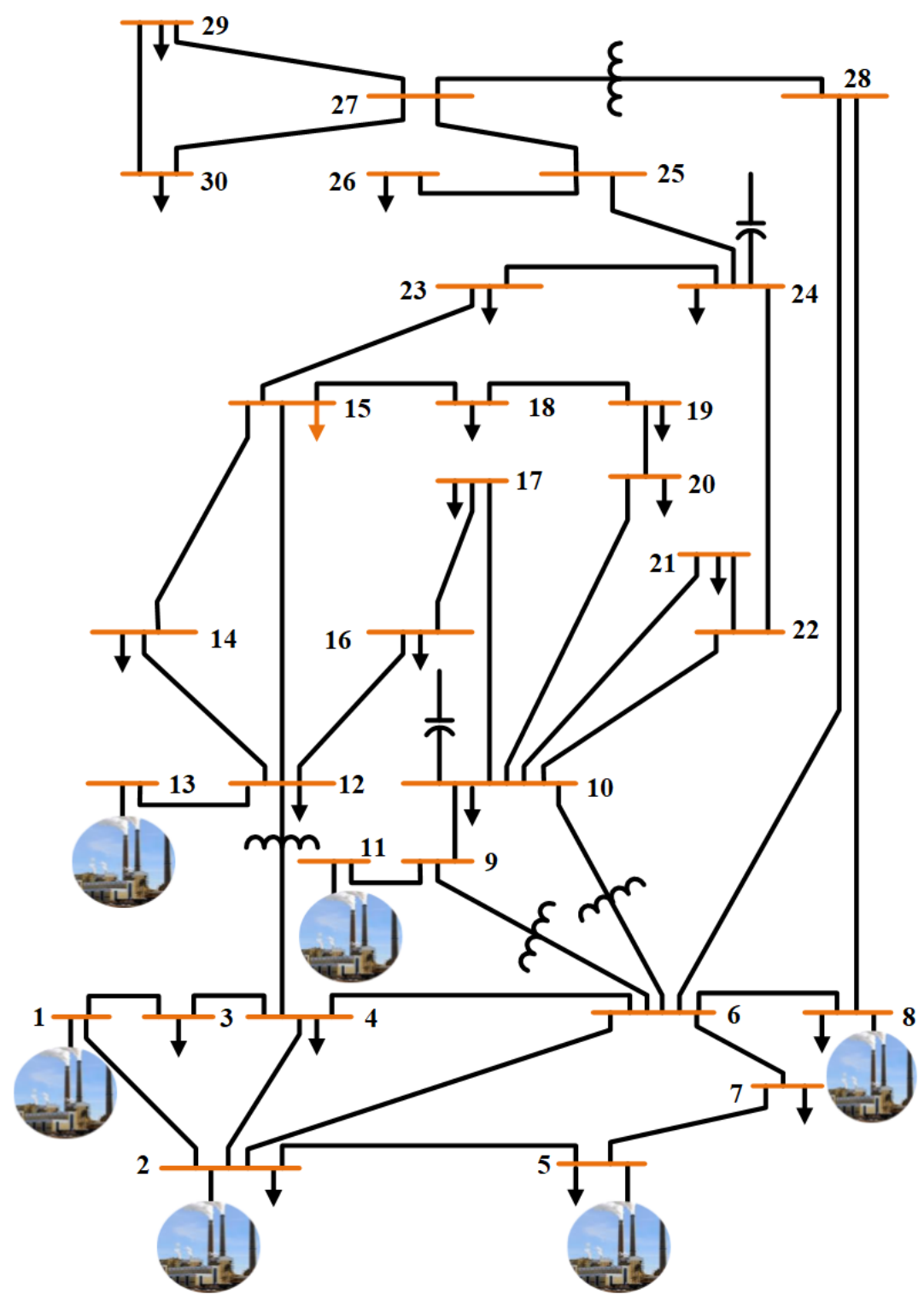

Figure 1. scenario 1: IEEE 30-bus system

- Test system 2: wind integrated IEEE 30-bus system

In this system, the IEEE 30-bus system is modified by replacing the thermal power generating units at buses 5, 11, and13 with wind power generators. Moreover, new two wind generators have been added at buses 24, and 30, as seen in Figure 2 .The objective functions defined in Section 2.2 is modified by adding the output power of wind plants $\left(P_{w}(v)\right)$ given in Section 3. Case 3 and case 5 described in Section 2.2 are modified by adding the total cost of wind plants $\left(C_{T}^{w}\right)$ defined in Section 3 . The general specifications of this system and the data of wind power plants are given in Table 4 and Table 5, respectively.

Table 5. Data of wind power plant for test system 2.

\begin{tabular}{cccccccccccc}
\hline Unit & Bus & No. of Turbines & $P_{w r}[\mathrm{MW}]$ & $\mathrm{k}$ & $\mathrm{c}$ & $g_{i}[\$ / \mathrm{MWH}]$ & $K_{R w, i}[\$ / \mathrm{MWH}]$ & $K_{P w, i}[\$ / \mathrm{MWH}]$ & $v_{\text {in }}[\mathrm{m} / \mathrm{s}]$ & $v_{\text {out }}[\mathrm{m} / \mathrm{s}]$ & $v_{r}[\mathrm{~m} / \mathrm{s}]$ \\
\hline 1 & 5 & 12 & 2 & 2 & 9 & 1.65 & 2.6 & 1.5 & 4 & 25 \\
\hline 2 & 11 & 12 & 2 & 2 & 10 & 1.6 & 2.6 & 1.5 & 4 & 25 \\
\hline 3 & 13 & 12 & 2 & 2 & 9 & 1.6 & 2.6 & 1.5 & 4 & 13 \\
\hline 4 & 24 & 15 & 2 & 2 & 10 & 1.65 & 2.6 & 1.5 & 4 & 25 \\
\hline 5 & 30 & 15 & 2 & 2 & 9 & 1.7 & 2.6 & 1.5 & 4 & 25 \\
\hline
\end{tabular}




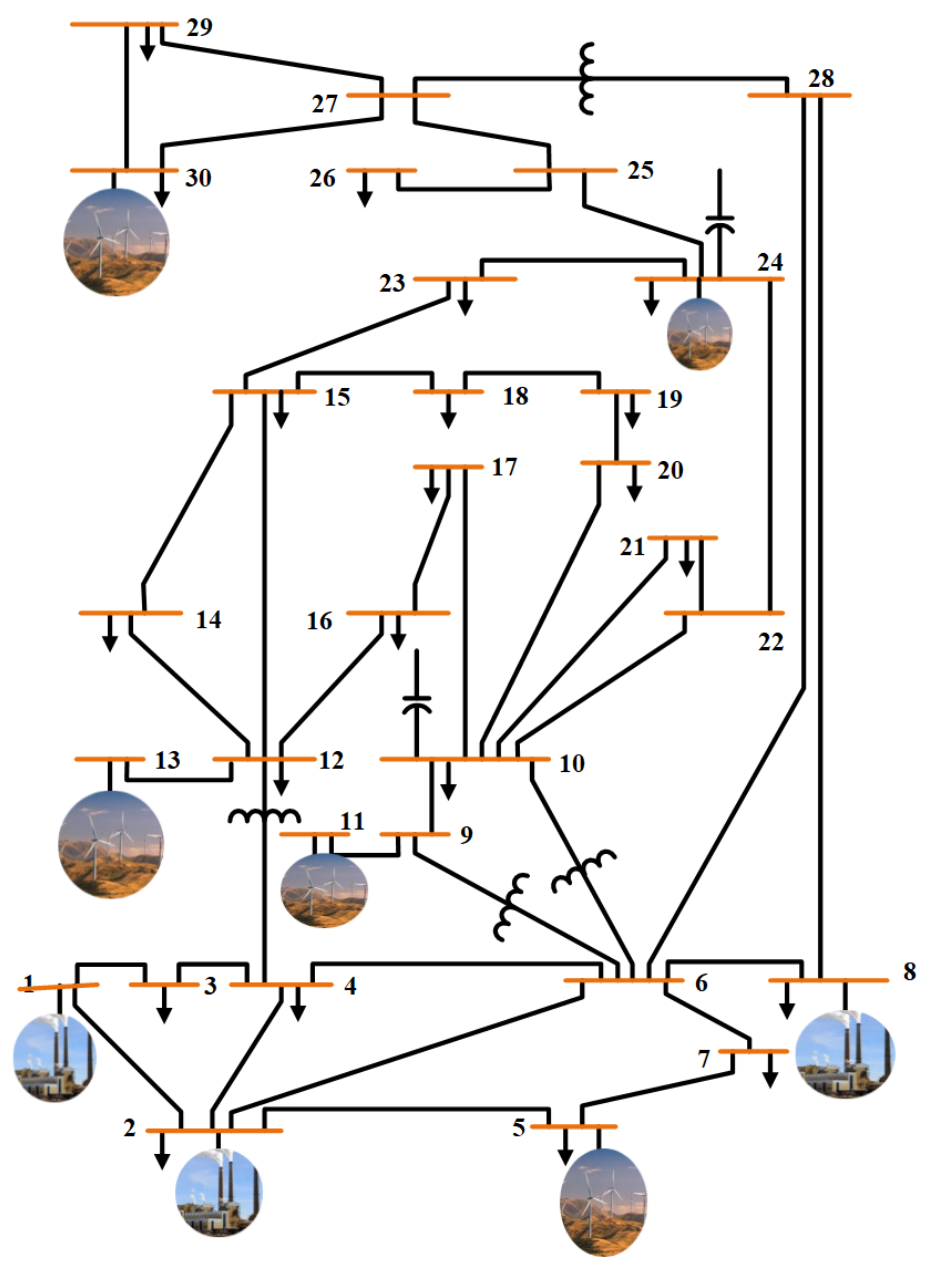

Figure 2. Wind integrated IEEE 30-bus system.

- Test system 3: Solar PV integrated IEEE 30-bus system

This system is modified by locating solar PV generators at buses 5, 11, and13 instead of the thermal power generators. Furthermore, two new solar power generation units are installed at buses 24, and 30, as shown in Figure 3.The objective funtions defined in Section2.2 are modified by adding the output power of solar PV plants $\left(P_{S}(G)\right)$ given in Section 3. Case 3 and case 5 described in Section 2.2 are modified by adding the total cost of solar PV plants $\left(C_{T}^{P V}\right)$ defined in Section 3. The general data of this system and solar PV plants are presented in Table4 and Table 6, respectively.

Table 6. Data of solar power plant for test system 3.

\begin{tabular}{cccccccccc}
\hline Unit & Bus & $P_{s r}[\mathbf{M W}]$ & $G_{s t d}\left[\mathbf{W} / m^{2}\right]$ & $R_{c}\left[\mathbf{W} / m^{2}\right]$ & $\mu$ & $\sigma$ & $h_{k}[\mathbf{\$} / \mathbf{M W h}]$ & $K_{P s, k}[\mathbf{\$} / \mathbf{M W h}]$ & $K_{R s, k}[\mathbf{\$} / \mathbf{M W h}]$ \\
\hline 1 & 5 & 24 & 800 & 170 & 6 & 0.6 & 1.55 & 3.2 & 1.3 \\
\hline 2 & 11 & 24 & 800 & 200 & 6 & 0.6 & 1.45 & 2.8 & 1.3 \\
\hline 3 & 13 & 24 & 800 & 170 & 6 & 0.6 & 1.6 & 3.1 & 1.45 \\
\hline 4 & 24 & 30 & 800 & 170 & 6 & 0.6 & 1.6 & 3 & 1.3 \\
\hline 5 & 30 & 30 & 800 & 200 & 6 & 0.6 & 1.6 & 3 & 1.3 \\
\hline
\end{tabular}




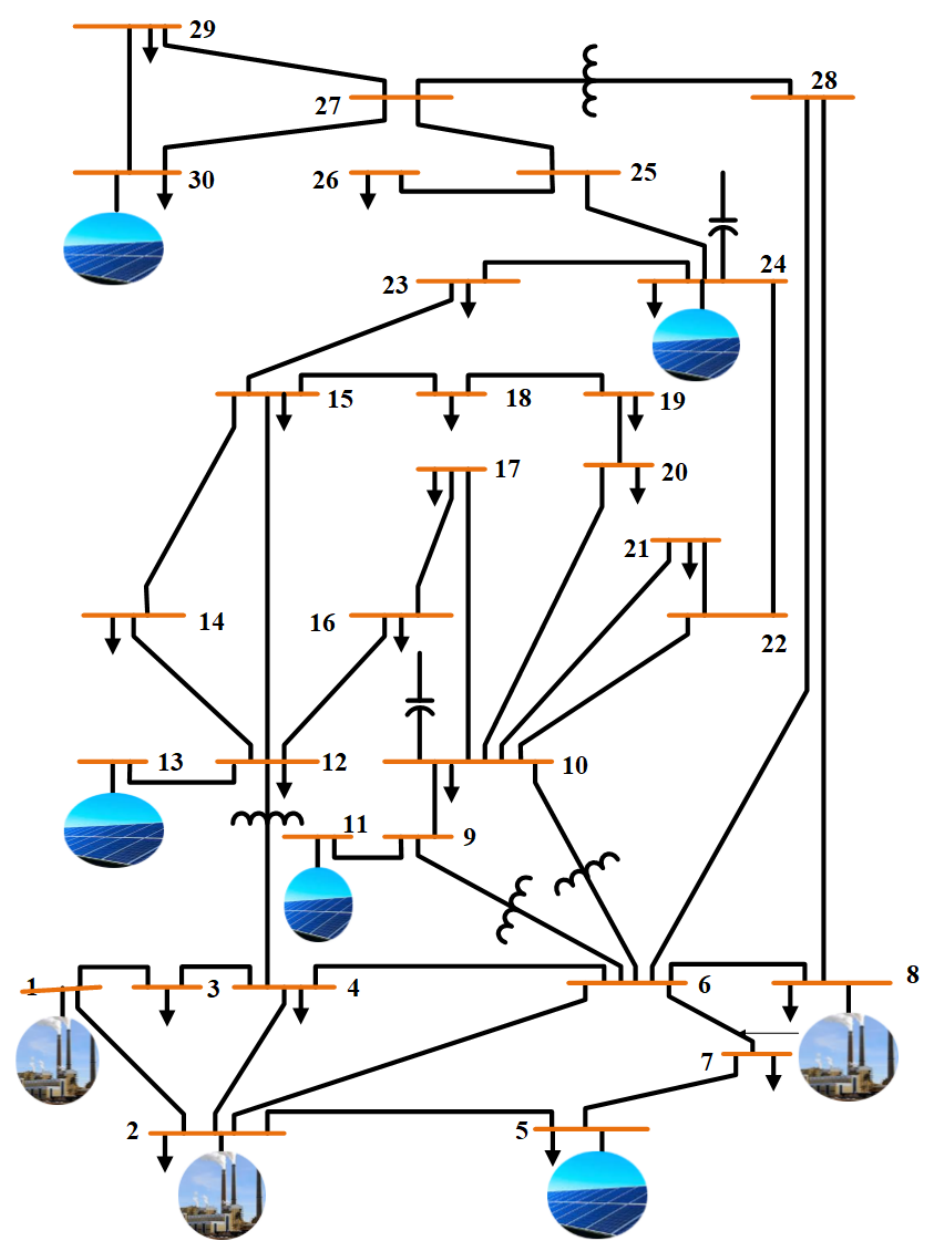

Figure 3. Solar PV integrated IEEE 30-bus system.

- Test system 4: Hybrid wind and solar PV integrated IEEE 30-bus system

This modified test power system is simulated to show its behavior in the presence of both wind and solar PV power generating units, as depicted in Figure 4. The IEEE 30-bus system has been modified by replacing the thermal power generating units at buses 5, 11, and 13 with wind generator at bus 11 and solar PV at buses 5 and 13. In addition, the new solar PV and wind power generators are constructed at bus 24, and 30, respectively. The objective functions defined in Section 2.2 are modified by adding the output power of solar PV plants $\left(P_{s}(G)\right)$ and the output power of wind plants $\left(P_{w}(v)\right)$ given in Section 3. Case 3 and case 5 described in Section 2.2 are modified by adding the total cost of solar PV plants $\left(C_{T}^{P V}\right)$ and the total cost of wind plants $\left(C_{T}^{w}\right)$ defined in Section 3. The specification of this hybrid power system is given in Table 4. The data of wind and solar PV plants are described in Table 7, and Table 8, respectively.

Table 7. Data of wind power plant for test system 4.

\begin{tabular}{cccccccccccc}
\hline Unit & Bus & No. of Turbines & $P_{w r}[\mathrm{MW}]$ & $\mathrm{k}$ & $\mathrm{c}$ & $g_{i}[\$ / \mathrm{MWH}]$ & $K_{R w, i}[\$ / \mathrm{MWH}]$ & $K_{P w, i}[\$ / \mathrm{MWH}]$ & $v_{\text {in }}[\mathrm{m} / \mathrm{s}]$ & $v_{\text {out }}[\mathrm{m} / \mathrm{s}]$ & $v_{r}[\mathrm{~m} / \mathrm{s}]$ \\
\hline 1 & 11 & 12 & 2 & 2 & 9 & 1.7 & 2.8 & 1.7 & 4 & 25 \\
\hline 2 & 30 & 12 & 2 & 2 & 10 & 1.7 & 2.8 & 1.7 & 4 & 25 \\
\hline
\end{tabular}

Table 8. Data of solar power plant for test system 4.

\begin{tabular}{cccccccccc}
\hline Unit & Bus & $P_{s r}[\mathbf{M W}]$ & $G_{s t d}\left[\mathbf{W} / m^{2}\right]$ & $R_{c}\left[\mathbf{W} / m^{2}\right]$ & $\mu$ & $\sigma$ & $h_{k}[\mathbf{S} / \mathbf{M W h}]$ & $K_{P s, k}[\mathbf{\$} / \mathbf{M W h}]$ & $K_{R s, k}[\mathbf{\$} / \mathbf{M W h}]$ \\
\hline 1 & 5 & 24 & 800 & 170 & 6 & 0.6 & 1.55 & 3.2 & 1.3 \\
\hline 2 & 13 & 30 & 800 & 170 & 6 & 0.6 & 1.45 & 3.1 & 1.45 \\
\hline 3 & 30 & 30 & 800 & 200 & 6 & 0.6 & 1.6 & 3 & 1.3 \\
\hline
\end{tabular}




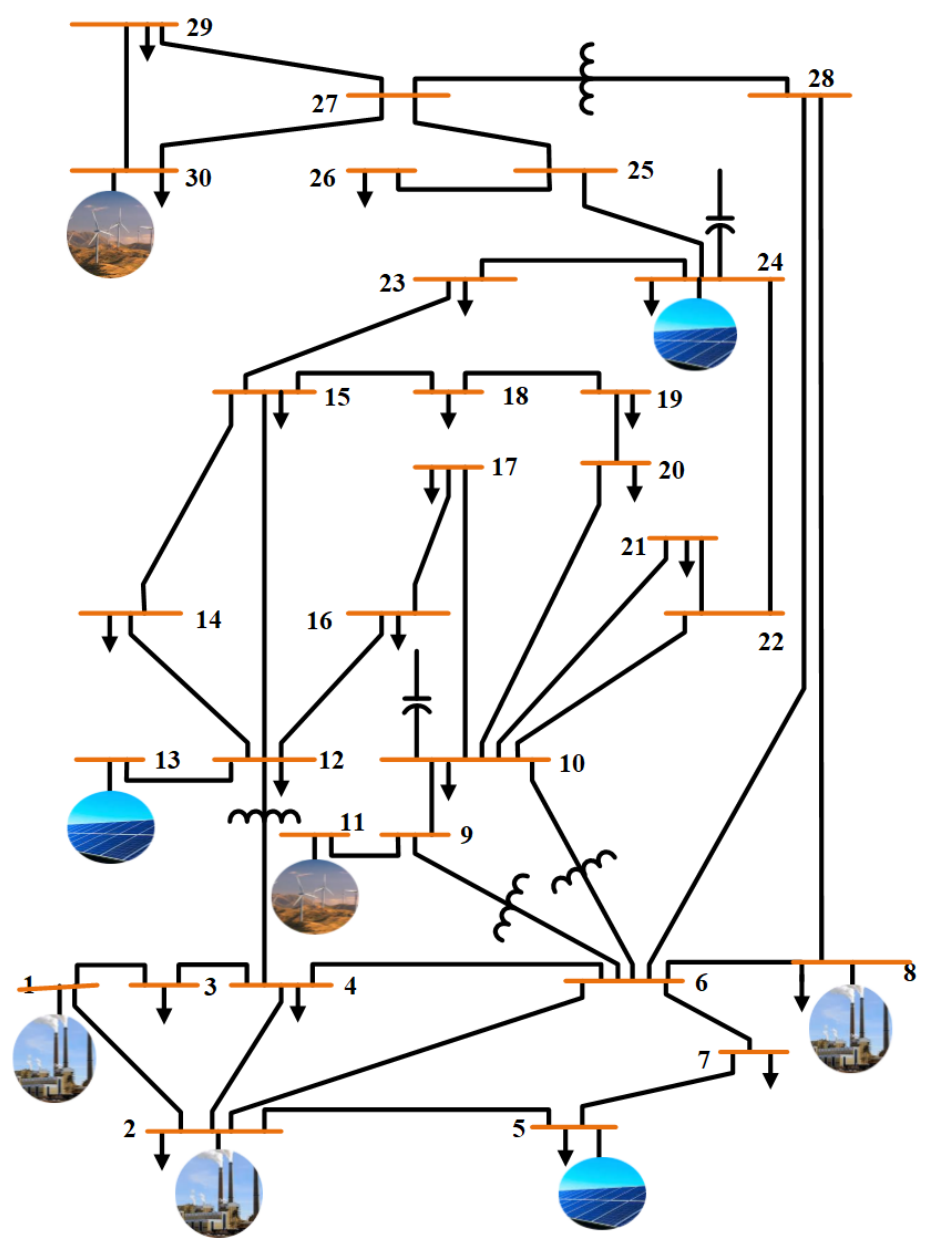

Figure 4. Hybrid wind and solar PV integrated IEEE 30-bus system.

\subsection{Discussion and analysis of the objective functions of $O P F$}

\subsubsection{Minimization of real power loss}

The EO [35], TLBO [45], MPSO [44], MFO [43], AGPSO1 [44], and TACPSO [44] algorithms are implemented on the test system 1 , test system 2, test system 3 , and test system 4 for the minimization of the real power loss as defined in Section 2.2. Fig. 5a shows the convergence characteristics of real power loss yielded by the best solution of the EO and other optimization methods for test system1. It observed that the better convergence characteristic is yielded by the EO. Furthermore, Fig. 5b and Fig.5c display voltage and loading profiles of test system 1 for case 1 . It is clear that the EO and other optimization methods obey the voltage limits of buses and loading limits of transmission lines. The results of EO and other techniques for test system 1 are displayed in Table 9

Table 9. Results of EO and other methods of case 1 for test system 1.

\begin{tabular}{ccccccc}
\hline & MFO & TACPSO & AGPSO1 & TLBO & EO & MPSO \\
\hline$V D($ p.u. $)$ & 0.867649 & 0.898003 & 0.898362 & 0.87350728 & 0.917249 & 0.679794 \\
$F C(\$ / \mathrm{h})$ & 967.4482 & 967.6206 & 967.6485 & 967.2492825 & 967.5865 & 967.7676 \\
$P_{\text {loss }}(\mathrm{MW})$ & 3.124412 & 3.100891 & 3.094156 & 3.108417583 & 3.087342 & 3.144079 \\
$E($ ton $/ \mathrm{h})$ & 0.207299 & 0.207259 & 0.207266 & 0.207286164 & 0.207268 & 0.207273 \\
\hline$f_{o}$ & 3.124412 & 3.100891 & 3.094156 & 3.108417583 & 3.087342 & 3.144079 \\
\hline
\end{tabular}




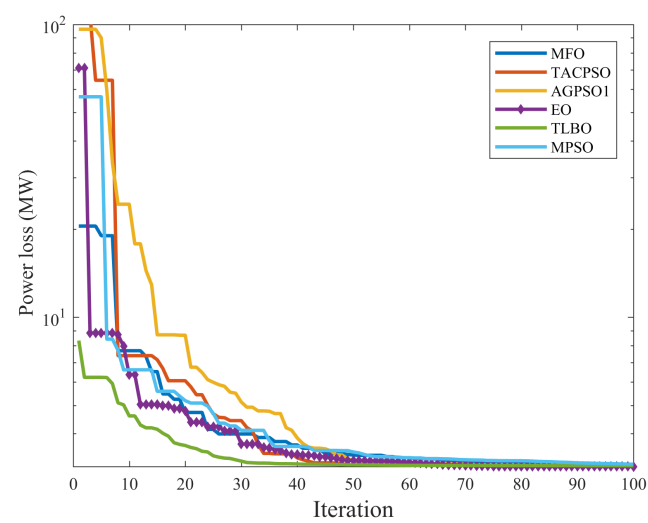

(a) Comparative convergence curves.

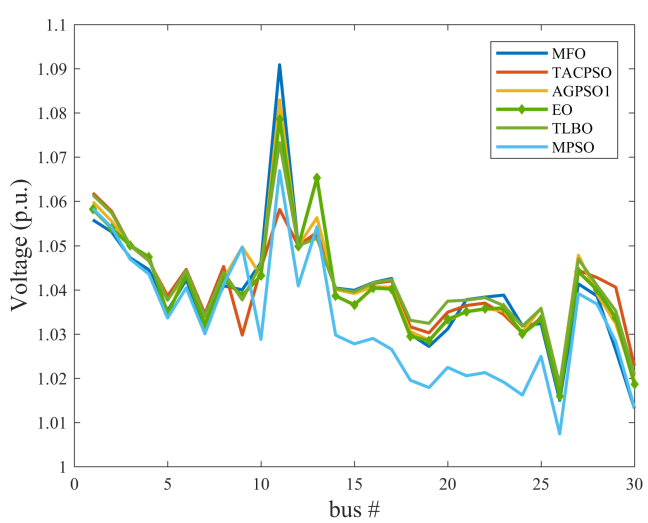

(b) Voltage profile.

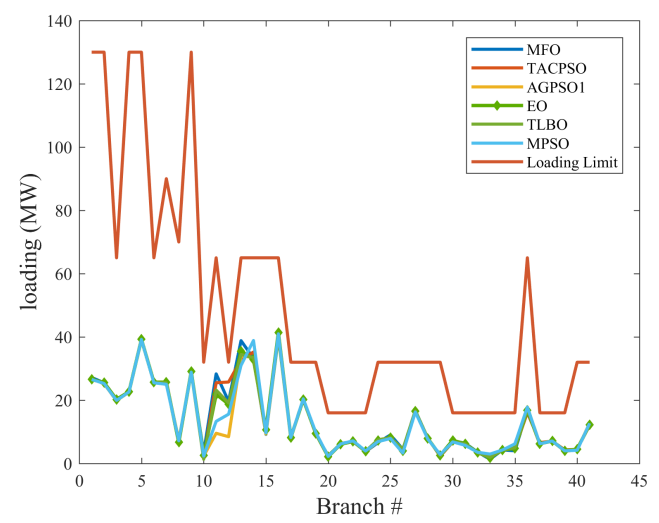

(c) Loading Profile

Figure 5. Comparative convergence, voltage and loading profiles for case 1 for all test systems.

The loss and loading profiles using EO for all test systems are given in Fig. 6.The optimal (best) results yielded by the EO method for the test system 1, test system 2, test system 3, and test system 4 are tabulated in Table 10.From Fig.6 and Table 10, it is seen that the losses of test system 2, test system 3, and test system 4 reduced by $23.6 \%, 31.52 \%$, and $33.32 \%$, respectively compared to test system 1 .

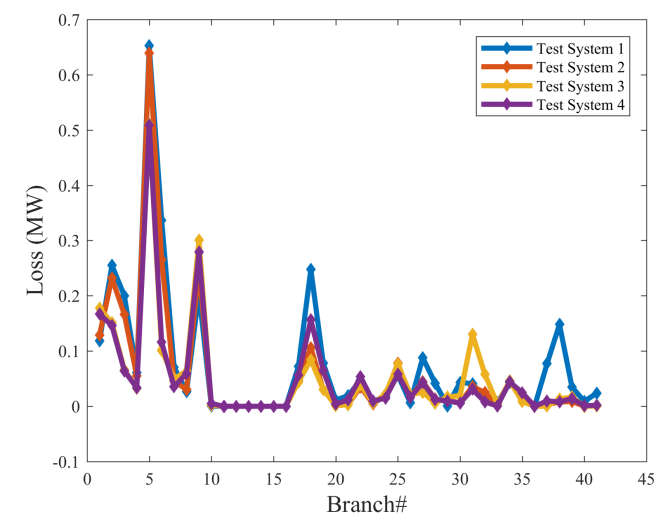

(a) Loss profile.

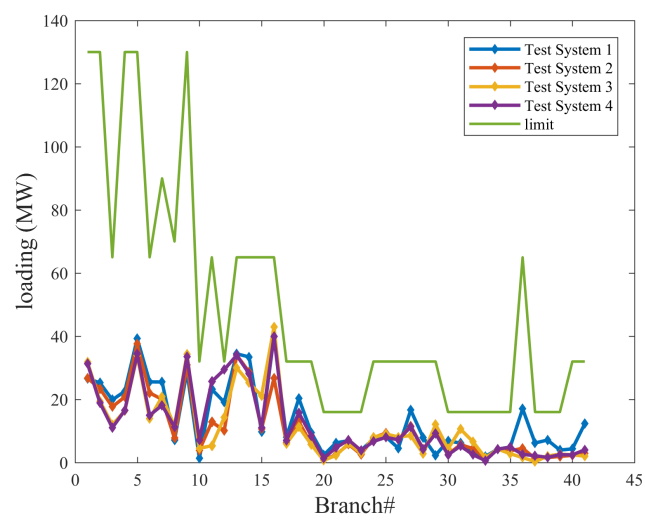

(b) Loading Profile

Figure 6. Loss and loading Profiles of case 1 for all test systems using EO. 
Table 10. Optimal settings of control variables for case 1 for all test systems using EO.

\begin{tabular}{|c|c|c|c|c|c|c|}
\hline Parameters & Min & Max & Test system 1 & Test system 2 & Test system 3 & Test system 4 \\
\hline PG2 (MW) & 20 & 80 & 79.9983006 & 72.14028714 & 48.22886744 & 51.07651611 \\
\hline PG5 (MW) & 15 & 50 & 49.9982627 & 49.99945385 & 49.97347066 & 49.98470056 \\
\hline PG8 (MW) & 10 & 35 & 34.99453958 & 26.20234283 & 34.77838714 & 34.92764479 \\
\hline PG11 (MW) & 10 & 30 & 29.99984469 & 29.42347144 & 29.97517159 & 29.67713532 \\
\hline PG13 (MW) & 10 & 40 & 39.99027741 & 25.72695297 & 29.69711674 & 39.69895071 \\
\hline PG24 (MW) & 10 & 30 & & 18.61010237 & 27.4148297 & 15.73782289 \\
\hline PG30 (MW) & 10 & 40 & & 13.58641689 & 15.23102984 & 14.35575851 \\
\hline V1 (p.u.) & 0.95 & 1.1 & 1.061430345 & 1.033582214 & 1.037749499 & 1.056224426 \\
\hline V2 (p.u.) & 0.95 & 1.1 & 1.057379791 & 1.027683624 & 1.032739079 & 1.051241045 \\
\hline V5 (p.u.) & 0.95 & 1.1 & 1.037622078 & 1.003632229 & 1.013755431 & 1.032812731 \\
\hline V8 (p.u.) & 0.95 & 1.1 & 1.044007621 & 1.015022765 & 1.02707043 & 1.045463882 \\
\hline V11 (p.u.) & 0.95 & 1.1 & 1.073279794 & 1.063216144 & 0.999050197 & 1.042867188 \\
\hline V13 (p.u.) & 0.95 & 1.1 & 1.051619936 & 1.034701938 & 1.044856898 & 1.020563172 \\
\hline V24 (p.u.) & 0.95 & 1.1 & & 1.024480465 & 1.009002895 & 1.020352939 \\
\hline V30 (p.u.) & 0.95 & 1.1 & & 1.022453184 & 1.018925985 & 1.040981535 \\
\hline QC10 (MVAr) & 0 & 5 & 4.287709826 & 4.782286758 & 2.62406261 & 3.612693403 \\
\hline QC12 (MVAr) & 0 & 5 & 2.093601675 & 0.000803534 & 0.986423834 & 2.416935212 \\
\hline QC15 (MVAr) & 0 & 5 & 3.996488379 & 1.898614523 & 0.206692775 & 3.600783886 \\
\hline QC17 (MVAr) & 0 & 5 & 4.136235738 & 4.356883849 & 2.716911629 & 0.342465282 \\
\hline QC20 (MVAr) & 0 & 5 & 4.495134896 & 3.354513668 & 4.692404829 & 3.296807199 \\
\hline QC21 (MVAr) & 0 & 5 & 5 & 0.046094293 & 2.038284465 & 0.872744865 \\
\hline QC23 (MVAr) & 0 & 5 & 3.197386977 & 4.967912056 & 4.957773966 & 4.740324068 \\
\hline QC24 (MVAr) & 0 & 5 & 4.806462479 & 4.536993047 & 3.79952116 & 3.698494945 \\
\hline QC29 (MVAr) & 0 & 5 & 2.461175597 & 0.21865228 & 4.63994E-05 & 3.927880442 \\
\hline T11 (p.u.) & 0.9 & 1.1 & 1.055740955 & 1.015687471 & 1.020034326 & 1.0962353 \\
\hline T12 (p.u.) & 0.9 & 1.1 & 0.924042761 & 0.951998195 & 0.957069803 & 0.900424717 \\
\hline T15 (p.u.) & 0.9 & 1.1 & 0.988530694 & 0.989254661 & 1.094558386 & 0.991494831 \\
\hline T36 (p.u.) & 0.9 & 1.1 & 0.975749345 & 0.977273155 & 1.010207101 & 1.010623787 \\
\hline PG1 (MW) & 50 & 200 & 51.50611659 & 50.08572807 & 50.22954768 & 50.01396753 \\
\hline QG1 (MVAr) & -20 & 150 & -5.485983591 & -1.712627012 & -9.408754457 & -4.363894439 \\
\hline IVAr) & -20 & 60 & 7.5744 & 4137 & 0677 & 62082 \\
\hline QG5 (MVAr) & -15 & 62.5 & 21.13271229 & 17.01446382 & 19.68757038 & 20.6489489 \\
\hline QG8 (MVAr) & -15 & 48 & 26.41312254 & 26.16274206 & 28.52016815 & 33.06577869 \\
\hline QG11 (MVAr) & -10 & 40 & 19.21231862 & 19.38101083 & 0.13383456 & 18.93870787 \\
\hline QG13 (MVAr) & -15 & 44 & 2.247530335 & 8.029799729 & 33.49981989 & -2.320248965 \\
\hline QG24 (MVAr) & -15 & 44 & & 3.105401958 & 3.720374455 & 2.56415683 \\
\hline QG 30 (MVAr) & -15 & 44 & & 0.296246809 & 2.993820748 & 1.368798025 \\
\hline$V D$ (p.u.) & & & 0.917249187 & 0.367181831 & 0.252949566 & 0.482190403 \\
\hline$F C(\$ / \mathbf{h})$ & & & 967.5864625 & 417.7815499 & 358.1435956 & 368.1354088 \\
\hline$P_{\text {loss }}(\mathbf{M W})$ & & & 3.087341565 & 2.374755583 & 2.128420834 & 2.072496662 \\
\hline$E(\operatorname{ton} / \mathbf{h})$ & & & 0.20726839 & 0.09655031 & 0.09111361 & 0.091202895 \\
\hline$T C(\$ / \mathbf{h})$ & & & & 863.2203104 & 823.476285 & 867.8385329 \\
\hline$C_{T}^{W}(\mathbf{\$} / \mathbf{h})$ & & & & 141.4837171 & & 499.7031241 \\
\hline$C_{T}^{P V}(\mathbf{\$} / \mathbf{h})$ & & & & 303.9550435 & 465.3326895 & \\
\hline$f_{o}(\mathbf{M W})$ & & & 3.087341565 & 2.374755583 & 2.128420834 & 2.072496662 \\
\hline
\end{tabular}

The statistical results (the best, the worst, the mean, and the standard deviation) of the real power loss for the EO and other optimization techniques are given in Table 11. As shown in Table 11, the minimum best, standard deviation, and mean are resulted from the EO. 
Table 11. Summary of the statistical analysis of case 1 for test system 1 .

\begin{tabular}{ccccc}
\hline & Best & Worst & Mean & Std dev \\
\hline MFO & 3.124412 & 3.469255 & 3.313791 & 0.115148 \\
TACPSO & 3.100891 & 3.495604 & 3.162984 & 0.119564 \\
AGPSO1 & 3.094156 & 3.558659 & 3.136808 & 0.175963 \\
TLBO & 3.108418 & 3.271804 & 3.200392 & 0.057571 \\
EO & 3.087342 & 3.131426 & 3.089549 & 0.013218 \\
MPSO & 3.144079 & 3.417325 & 3.202598 & 0.080901 \\
\hline
\end{tabular}

As expected, the addition and location of the renewable energy resources in the power system have a significant impact on reducing the real power loss.

\subsubsection{Emission Index Minimization}

In this case, the emission index defined in section 2.2 was minimized for all test systems. Fig. 7 demonstrates the convergence characteristics, loss profiles, and loading profiles for emission minimization using EO and other methods. It can be noticed from Fig. 7a that the EO has the smoothest and speediest convergence curves in comparing with other techniques, as well as Fig.7b and Fig.7c show that there is no violation in the voltage limits of buses and loading limits of transmission lines.

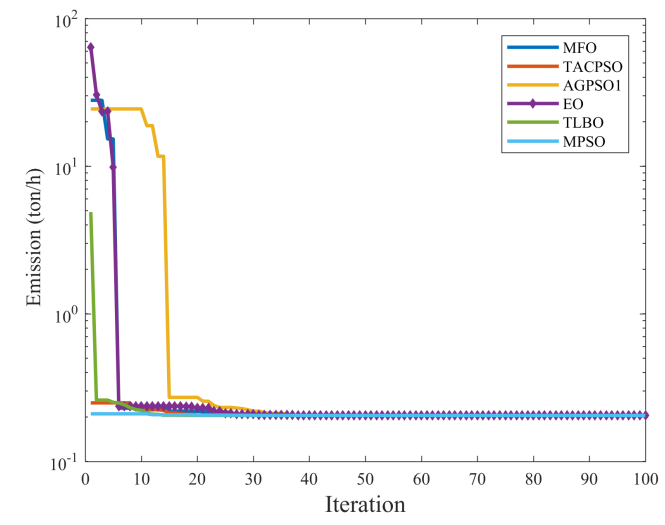

(a) Comparative convergence curves.

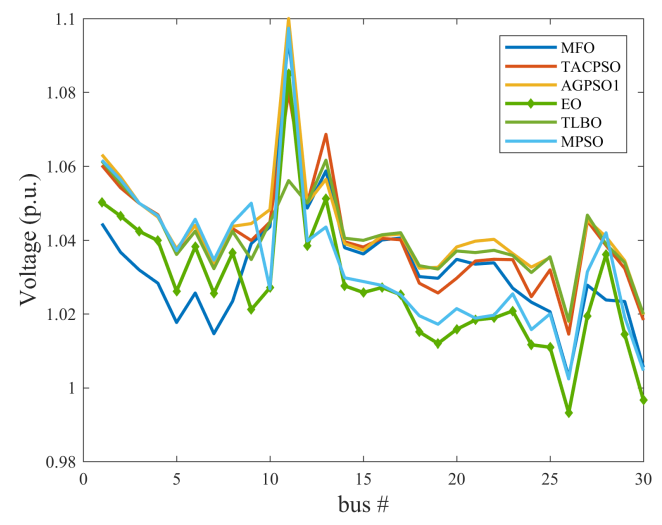

(b) Voltage profile.

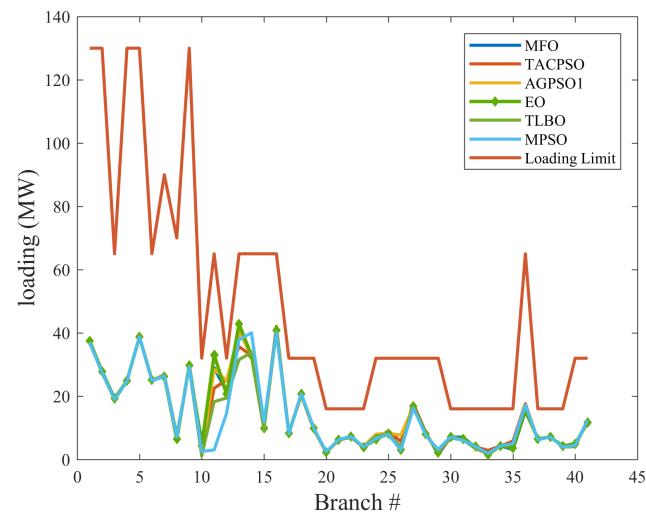

(c) Loading profile.

Figure 7. Comparative convergence, voltage and loading Profiles for case 2 for all test systems. 
The best (optimal) results obtained using the EO for all test systems for case 2 are shown in Table 12 .As we can see from Fig. 8 and Table 12 that emission index reduced by $55.54 \%$ for test system 2, test system 3, and test system 4 compared to test system 1 .

Table 12. Optimal settings of control variables for case2 for all test systems using EO.

\begin{tabular}{|c|c|c|c|c|c|c|}
\hline Parameters & Min & Max & Test system 1 & Test system 2 & Test system 3 & Test system 4 \\
\hline PG2 (MW) & 20 & 80 & 67.52765352 & 47.15393481 & 46.93784062 & 46.74579811 \\
\hline PG5 (MW) & 15 & 50 & 49.99976843 & 49.99997692 & 48.55695793 & 49.63943974 \\
\hline PG8 (MW) & 10 & 35 & 34.99979715 & 34.99785564 & 35 & 34.99981323 \\
\hline PG11 (MW) & 10 & 30 & 30 & 13.08937369 & 24.11263394 & 28.93951933 \\
\hline PG13 (MW) & 10 & 40 & 39.99994042 & 39.97364116 & 38.90979918 & 31.15977654 \\
\hline PG24 (MW) & 10 & 30 & & 29.67649489 & 20.72363213 & 13.68967898 \\
\hline PG30 (MW) & 10 & 40 & & 22.06349364 & 22.1793691 & 32.00183302 \\
\hline V1 (p.u.) & 0.95 & 1.1 & 1.0613919 & 1.035577033 & 1.017785294 & 1.007633877 \\
\hline V2 (p.u.) & 0.95 & 1.1 & 1.055299891 & 1.03014784 & 1.009596473 & 0.99225379 \\
\hline V5 (p.u.) & 0.95 & 1.1 & 1.036061646 & 0.975474909 & 0.982885915 & 0.966515297 \\
\hline V8 (p.u.) & 0.95 & 1.1 & 1.042336524 & 0.994262522 & 0.996877809 & 0.970873143 \\
\hline V11 (p.u.) & 0.95 & 1.1 & 1.056098162 & 0.99155371 & 1.066472978 & 1.018197794 \\
\hline V13 (p.u.) & 0.95 & 1.1 & 1.061630874 & 1.045591502 & 1.053301428 & 0.990382535 \\
\hline V24 (p.u.) & 0.95 & 1.1 & & 0.994310052 & 1.023161602 & 1.006430427 \\
\hline V30 (p.u.) & 0.95 & 1.1 & & 0.976743321 & 0.962066536 & 0.995194145 \\
\hline QC10 (MVAr) & 0 & 5 & 4.194820255 & 0.691891638 & 0 & 2.28917862 \\
\hline QC12 (MVAr) & 0 & 5 & 0.527663733 & 3.89808945 & 4.781805725 & 0.003693677 \\
\hline QC15 (MVAr) & 0 & 5 & 4.925786364 & 0.093781976 & 4.681393138 & 3.767863825 \\
\hline QC17 (MVAr) & 0 & 5 & 4.982842903 & 2.766984513 & 4.998326488 & 4.887538377 \\
\hline QC20 (MVAr) & 0 & 5 & 4.671024822 & 4.426843395 & 4.610963598 & 5 \\
\hline QC21 (MVAr) & 0 & 5 & 4.976075346 & 1.329009086 & 4.940763823 & 2.759967479 \\
\hline QC23 (MVAr) & 0 & 5 & 2.74762835 & 3.54838243 & 0.002439547 & 4.271161763 \\
\hline QC24 (MVAr) & 0 & 5 & 4.992557282 & 0.606928317 & 0.970384621 & 2.50397663 \\
\hline QC29 (MVAr) & 0 & 5 & 2.088379542 & 4272 & 38444 & 2.957731038 \\
\hline T11 (p.u.) & 0.9 & 1.1 & 1.045594251 & 0.951879814 & 0.938502294 & 0.940072546 \\
\hline T12 (p.u.) & 0.9 & 1.1 & 0.921878284 & 0.962206441 & 1.096587454 & 0.919312335 \\
\hline T15 (p.u.) & 0.9 & 1.1 & 1.00248085 & 1.099174642 & 1.018026147 & 1.023627655 \\
\hline T36 (p.u.) & 0.9 & 1.1 & 0.972355171 & 0.92579926 & 1.099689643 & 1.060629423 \\
\hline PG1 (MW) & 50 & 200 & 64.09434175 & 50.00003511 & 50.00023516 & 50.00000501 \\
\hline QG1 (MVAr) & -20 & 150 & -5.544691231 & 0.054641352 & -1.33241509 & 18.58616272 \\
\hline QG2 (MVAr) & -20 & 60 & 6.45002148 & 47.44923402 & 4.202024706 & 1.97952536 \\
\hline QG5 (MVAr) & -15 & 62.5 & 21.67156016 & -1.442938766 & 13.43474762 & 19.83503047 \\
\hline QG8 (MVAr) & -15 & 48 & 27.29675405 & 23.11453954 & 7.583267029 & 12.95707181 \\
\hline QG11 (MVAr) & -10 & 40 & 11.72500454 & -6.137543909 & 13.66528344 & 1.654000716 \\
\hline QG13 (MVAr) & -15 & 44 & 9.840166661 & 39.23629311 & 21.68524583 & 6.151027816 \\
\hline QG24 (MVAr) & -15 & 44 & & 1.089772208 & 24.29742231 & 20.10756016 \\
\hline QG 30 (MVAr) & -15 & 44 & & -13.49116551 & 0.162345045 & 0.721702425 \\
\hline$V D$ (p.u.) & & & 0.9004031 & 0.298468513 & 0.404641642 & 0.391340877 \\
\hline$F C(\$ / \mathbf{h})$ & & & 944.2808599 & 354.7638857 & 354.038595 & 353.3864113 \\
\hline$P_{\text {loss }}(\mathbf{M W})$ & & & 3.22150126 & 3.554805885 & 3.020468191 & 3.775864192 \\
\hline$E($ ton/h) & & & 0.204818699 & 0.091061921 & 0.091060623 & 0.091060048 \\
\hline$T C(\$ / \mathbf{h})$ & & & & 877.5739313 & 865.4758094 & 867.8663197 \\
\hline$C_{T}^{W}(\mathbf{\$} / \mathbf{h})$ & & & & 108.3986993 & & 514.4799085 \\
\hline$C_{T}^{P V}(\mathbf{S} / \mathbf{h})$ & & & & 414.4113463 & 511.4372144 & \\
\hline$f_{o}($ ton $/ \mathbf{h})$ & & & 0.204818699 & 0.091061921 & 0.091060623 & 0.091060048 \\
\hline
\end{tabular}




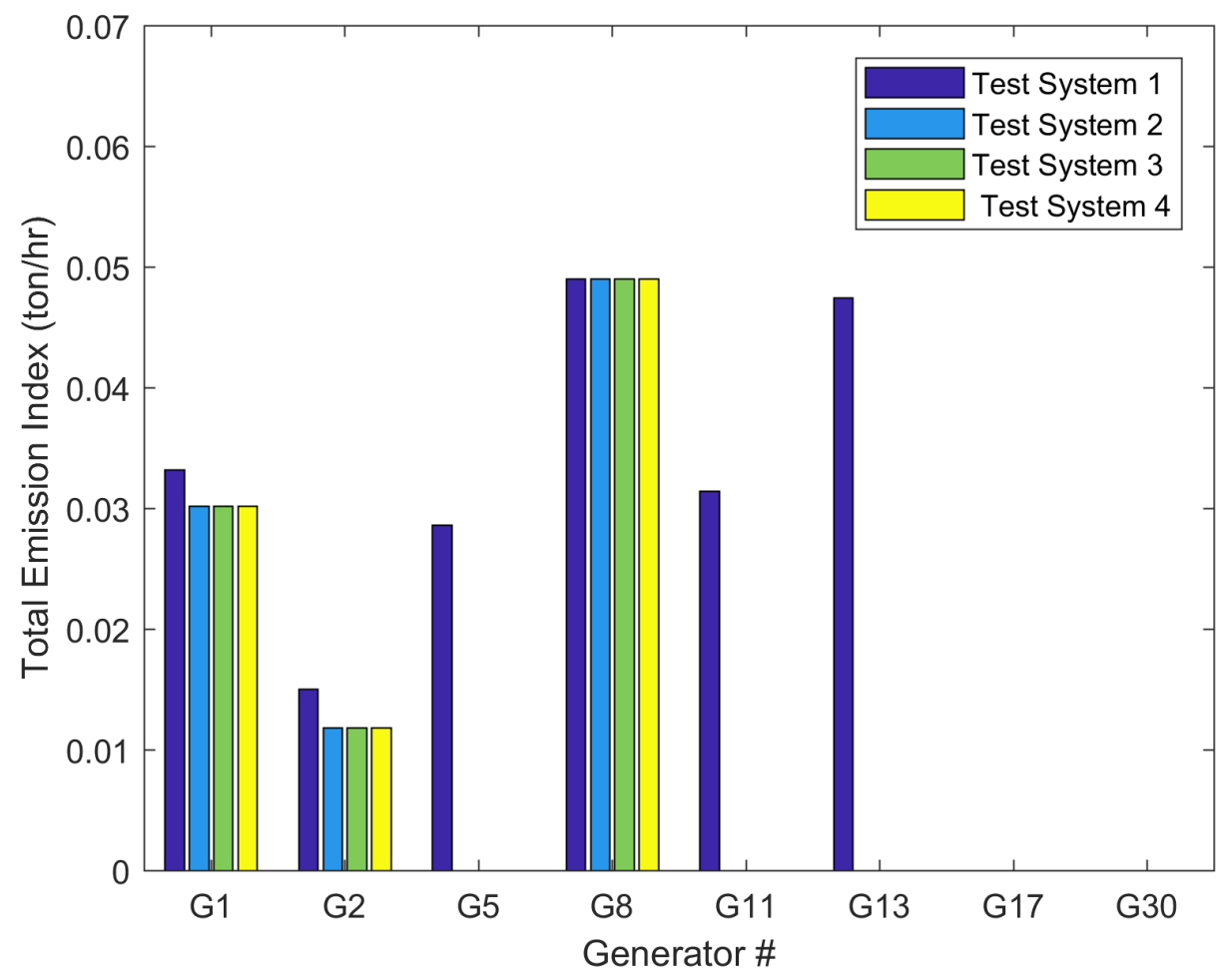

Figure 8. Total Emission index (ton/hr) of case 2 for all test systems using EO.

Table 13 summarizes the statistical results for the present case. It can be found from Table 13 that the EO provides the smallest best, standard deviation, and median than other methods.

Table 13. Summary of the statistical analysis of case 2 for test system 1.

\begin{tabular}{ccccc}
\hline & Best & Worst & Mean & Std dev \\
\hline MFO & 0.204862 & 0.204997 & 0.20495 & $4.15 \mathrm{E}-05$ \\
TACPSO & 0.204839 & 0.205089 & 0.204943 & $9.14 \mathrm{E}-05$ \\
AGPSO1 & 0.204823 & 0.204999 & 0.204921 & $5.14 \mathrm{E}-05$ \\
TLBO & 0.204855 & 0.204931 & 0.204892 & $2.43 \mathrm{E}-05$ \\
EO & 0.204819 & 0.204878 & 0.204834 & $1.78 \mathrm{E}-05$ \\
MPSO & 0.204833 & 0.20497 & 0.204934 & $5.44 \mathrm{E}-05$ \\
\hline
\end{tabular}

Table 14 presents the results of the EO and other methods for test system 1 with the minimization of emission index. For example, the objective function of case 2 for EO was 0.204819 ton/h compared to 0.204862 ton/h and 0.204885 ton/h for MFO [43] and TLBO [45] algorithms, respectively.

Table 14. Results of EO and other methods of case 2 for test system 1.

\begin{tabular}{ccccccc}
\hline & MFO & TACPSO & AGPSO1 & TLBO & EO & MPSO \\
\hline$V D($ p.u. $)$ & 0.702001 & 0.856848 & 0.921129 & 0.541768425 & 0.900403 & 0.661504 \\
$F C(\$ / \mathrm{h})$ & 944.3434 & 944.6554 & 944.3977 & 944.6873755 & 944.2809 & 944.4382 \\
$P_{\text {loss }}(\mathrm{MW})$ & 3.356033 & 3.286856 & 3.235581 & 3.336091467 & 3.221501 & 3.267419 \\
$E($ ton $/ \mathrm{h})$ & 0.204862 & 0.204839 & 0.204823 & 0.204854728 & 0.204819 & 0.204833 \\
\hline$f_{o}($ ton $/ \mathrm{h})$ & 0.204862 & 0.204839 & 0.204823 & 0.204854728 & 0.204819 & 0.204833 \\
\hline
\end{tabular}




\subsubsection{Minimization of the total cost of generating units}

The comparative convergence characteristics, loading profiles, and loss profiles for test system 1 for the EO and other optimization techniques are presented in Fig.9. As observed in Fig.9, the voltage and loading profiles are kept within the acceptable ranges and the EO gives the best convergence characteristics compared to other methods. The optimal results of the EO and other techniques for test system 1 are summarized in Table 15. From Table 15 , the EO leads to $800.4486 \$ / \mathrm{hr}$ total cost of generators which is better than the total cost obtained by the other compared methods.

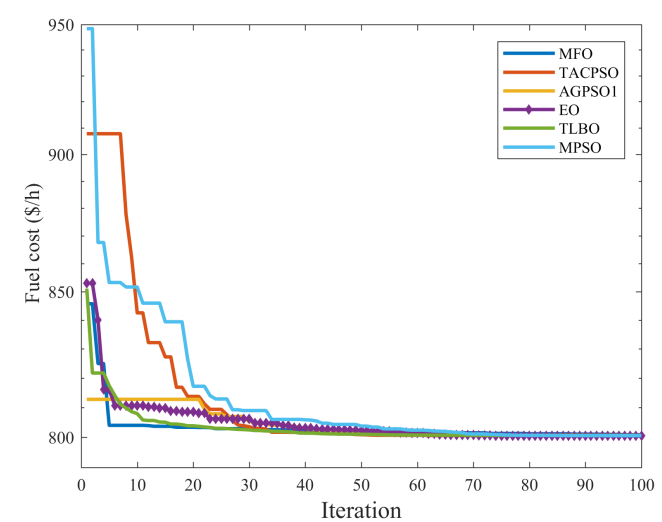

(a) Comparative convergence curves.

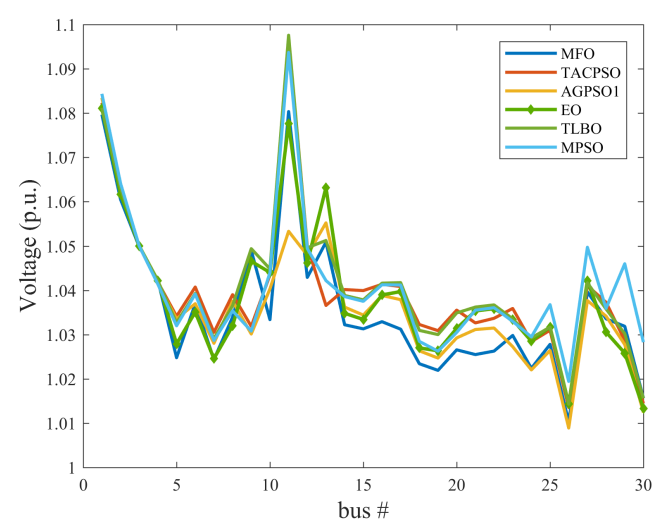

(b) Voltage profile.

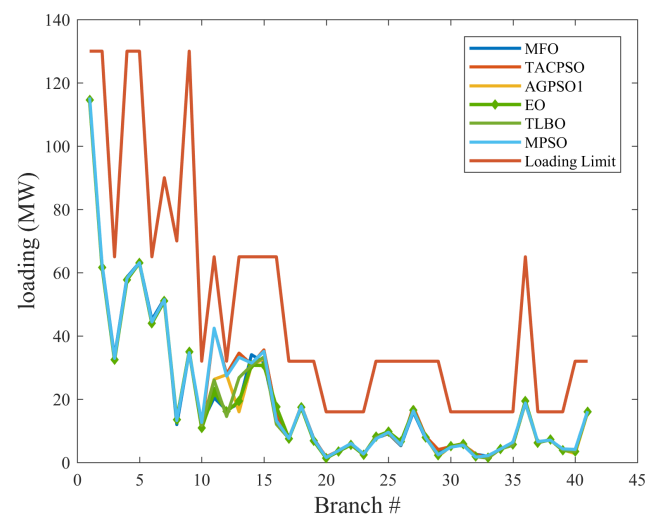

(c) Loading Profile

Figure 9. Comparative convergence, voltage and loading Profiles for case 3 for all test systems.

Table 15. Results of EO and other methods of case 3 for test system 1.

\begin{tabular}{ccccccc}
\hline & MFO & TACPSO & AGPSO1 & TLBO & EO & MPSO \\
\hline$V D$ (p.u.) & 0.740965 & 0.845878 & 0.761669 & 0.811019872 & 0.865075 & 0.877139 \\
$F C(\$ / \mathrm{h})$ & 800.8283 & 800.5201 & 800.5595 & 800.616176 & 800.4486 & 800.5346 \\
$P_{\text {loss }}(\mathrm{MW})$ & 9.134902 & 9.02898 & 9.040104 & 8.97569702 & 9.041464 & 9.059254 \\
$E$ (ton $/ \mathrm{h})$ & 0.366492 & 0.366315 & 0.365967 & 0.363482104 & 0.367478 & 0.366949 \\
\hline$f_{o}(\$ / \mathrm{h})$ & 800.8283 & 800.5201 & 800.5595 & 800.616176 & 800.4486 & 800.5346 \\
\hline
\end{tabular}

The statistical results yielded by the EO and other optimization techniques are given in Table16. 
Table 16. Summary of the statistical analysis of case 3 for test system 1 .

\begin{tabular}{ccccc}
\hline & Best & Worst & Mean & Std dev \\
\hline MFO & 800.8283 & 802.8078 & 801.5102 & 0.72899 \\
TACPSO & 800.5201 & 804.0448 & 800.6766 & 1.305504 \\
AGPSO1 & 800.5595 & 802.1145 & 800.7023 & 0.453581 \\
TLBO & 800.6162 & 802.225 & 800.8366 & 0.471362 \\
EO & 800.4486 & 800.646 & 800.4793 & 0.057894 \\
MPSO & 800.5346 & 804.6442 & 801.1155 & 1.810857 \\
\hline
\end{tabular}

From Table 17 and Fig.10, it can be observed that the total cost of generating units for test system 2, test system 3 , and test system 4 declined by $3.54 \%, 3.47 \%$, and $2.91 \%$, respectively compared to test system 1 .

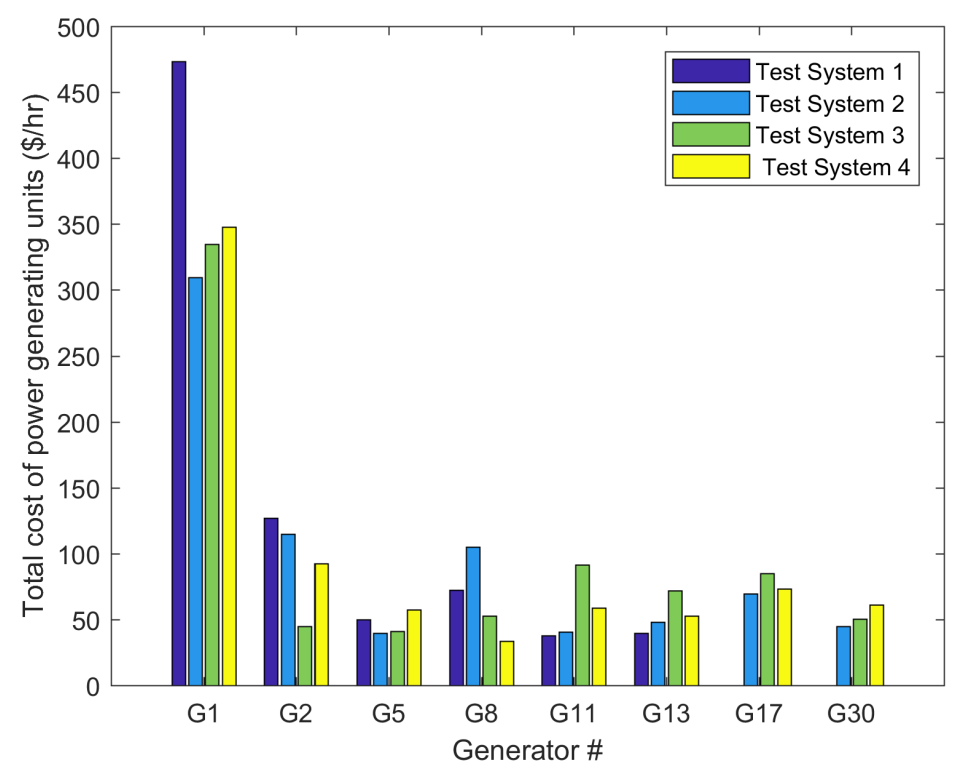

Figure 10. Total cost of generating units of case 3 for all test systems using EO. 
Table 17. Optimal settings of control variables for case 3 for all test systems using EO.

\begin{tabular}{|c|c|c|c|c|c|c|}
\hline Parameters & Min & Max & Test system 1 & Test system 2 & Test system 3 & Test system 4 \\
\hline PG2 (MW) & 20 & 80 & 48.74605575 & 45.18712121 & 21.21838812 & 38.17119779 \\
\hline PG5 (MW) & 15 & 50 & 21.4315437 & 15.00195728 & 15.40668673 & 19.095538 \\
\hline PG8 (MW) & 10 & 35 & 21.18353338 & 29.97018297 & 15.60913424 & 10.08641797 \\
\hline PG11 (MW) & 10 & 30 & 11.52952165 & 13.07275916 & 29.402226 & 20.7452611 \\
\hline PG13 (MW) & 10 & 40 & 12.0107829 & 19.71387022 & 30.51540057 & 17.9328134 \\
\hline PG24 (MW) & 10 & 30 & & 27.19702311 & 26.3304831 & 25.32965431 \\
\hline PG30 (MW) & 10 & 40 & & 14.74139467 & 17.72178713 & 20.28023584 \\
\hline V1 (p.u.) & 0.95 & 1.1 & 1.081191705 & 1.022713246 & 1.02314065 & 1.059255936 \\
\hline V2 (p.u.) & 0.95 & 1.1 & 1.063110135 & 1.006065736 & 1.008766945 & 1.043719467 \\
\hline V5 (p.u.) & 0.95 & 1.1 & 1.032684857 & 0.956733982 & 0.961917138 & 1.009460201 \\
\hline V8 (p.u.) & 0.95 & 1.1 & 1.036543249 & 0.994159517 & 0.985269141 & 1.02095678 \\
\hline V11 (p.u.) & 0.95 & 1.1 & 1.097591909 & 1.012587735 & 1.049992902 & 1.0845661 \\
\hline V13 (p.u.) & 0.95 & 1.1 & 1.051244633 & 1.054638289 & 1.011514979 & 1.046208927 \\
\hline V24 (p.u.) & 0.95 & 1.1 & & 1.035583887 & 1.011800496 & 1.043496784 \\
\hline V30 (p.u.) & 0.95 & 1.1 & & 0.95 & 0.996591531 & 1.048407181 \\
\hline QC10 (MVAr) & 0 & 5 & 2.971616423 & 3.739491269 & 4.902790106 & 0.325756054 \\
\hline QC12 (MVAr) & 0 & 5 & 0.655177618 & 4.809891924 & 1.662706176 & 3.06145818 \\
\hline QC15 (MVAr) & 0 & 5 & 3.197516308 & 0.002648509 & 0.249875162 & 3.301750446 \\
\hline QC17 (MVAr) & 0 & 5 & 4.723716655 & 3.279961844 & 1.827574807 & 1.707154585 \\
\hline QC20 (MVAr) & 0 & 5 & 3.650622268 & 0.917150962 & 1.107119341 & 0.418013886 \\
\hline QC21 (MVAr) & 0 & 5 & 5 & 4.948708899 & 2.08610321 & 4.893042007 \\
\hline QC23 (MVAr) & 0 & 5 & 2.498554056 & 4.535914953 & 4.240774401 & 3.58924067 \\
\hline QC24 (MVAr) & 0 & 5 & 4.985418463 & 5 & 0 & 1.169769378 \\
\hline QC29 (MVAr) & 0 & 5 & 2.584313587 & 4.144114834 & 4.95463484 & 1.500067393 \\
\hline T11 (p.u.) & 0.9 & 1.1 & 1.027284076 & 1.048412041 & 1.099843892 & 0.985023037 \\
\hline T12 (p.u.) & 0.9 & 1.1 & 0.971275895 & 0.9 & 0.922169184 & 0.989956238 \\
\hline T15 (p.u.) & 0.9 & 1.1 & 0.972373363 & 1.002944153 & 1.006664961 & 0.991751478 \\
\hline T36 (p.u.) & 0.9 & 1.1 & 0.9815263 & 1.059841992 & 0.944073975 & 0.971316876 \\
\hline PG1 (MW) & 50 & 200 & 177.5400261 & 125.374001 & 133.7249716 & 138.0708394 \\
\hline QG1 (MVAr) & -20 & 150 & -0.570024945 & -0.833938199 & -5.669301771 & -1.647701957 \\
\hline QG2 (MVAr) & -20 & 60 & 19.80925666 & 13.30674022 & 30.0465083 & 18.91158888 \\
\hline QG5 (MVAr) & -15 & 62.5 & 25.58480054 & 6.160576051 & 11.07617293 & 21.00268292 \\
\hline QG8 (MVAr) & -15 & 48 & 23.28431397 & 23.75265502 & 14.5584729 & 21.65678972 \\
\hline QG11 (MVAr) & -10 & 40 & 25.55139519 & 8.157153402 & 35.09222447 & 19.52230631 \\
\hline QG13 (MVAr) & -15 & 44 & 1.335643081 & 21.55072062 & 12.13070192 & 7.287213883 \\
\hline QG24 (MVAr) & -15 & 44 & & 22.34214251 & 15.27252587 & 8.101017671 \\
\hline QG 30 (MVAr) & -15 & 44 & & -5.331414964 & -8.278410983 & -1.403218975 \\
\hline$V D$ (p.u.) & & & 0.865074691 & 0.312619858 & 0.288839815 & 0.653856503 \\
\hline$F C(\$ / \mathbf{h})$ & & & 800.4486031 & 529.3973749 & 432.2815387 & 473.5571537 \\
\hline$P_{\text {loss }}(\mathbf{M W})$ & & & 9.041463508 & 6.858309749 & 6.529077621 & 6.311958209 \\
\hline$E$ (ton/h) & & & 0.367478227 & 0.141650437 & 0.159248156 & 0.163097259 \\
\hline$T C(\$ / \mathbf{h})$ & & & & 772.2465456 & 772.781097 & 777.3121394 \\
\hline$C_{T}^{W}(\mathbf{\$} / \mathbf{h})$ & & & & 85.46692162 & & 303.7549857 \\
\hline$C_{T}^{P V}(\mathbf{\$} / \mathbf{h})$ & & & & 157.3822491 & 340.4995583 & \\
\hline$f_{o}(\$ / \mathbf{h})$ & & & 800.4486031 & 772.2465456 & 772.781097 & 777.3121394 \\
\hline
\end{tabular}




\subsubsection{Voltage Deviation Minimization}

Fig. 11 demonstrates the voltage profiles for all test systems for this case using EO.The optimal solution obtained by EO for test system 1, test system 2, test system 3, and test system 4 are tabulated in Table 18. As shown in Fig. 11 and Table 18, the presence of the renewable energy resources improves the voltage profiles and reduced the voltage deviation for test system 2, test system 3, and test system 4 by $22.46 \%, 37.39 \%$, and $29.61 \%$, respectively compared to test system 1 .

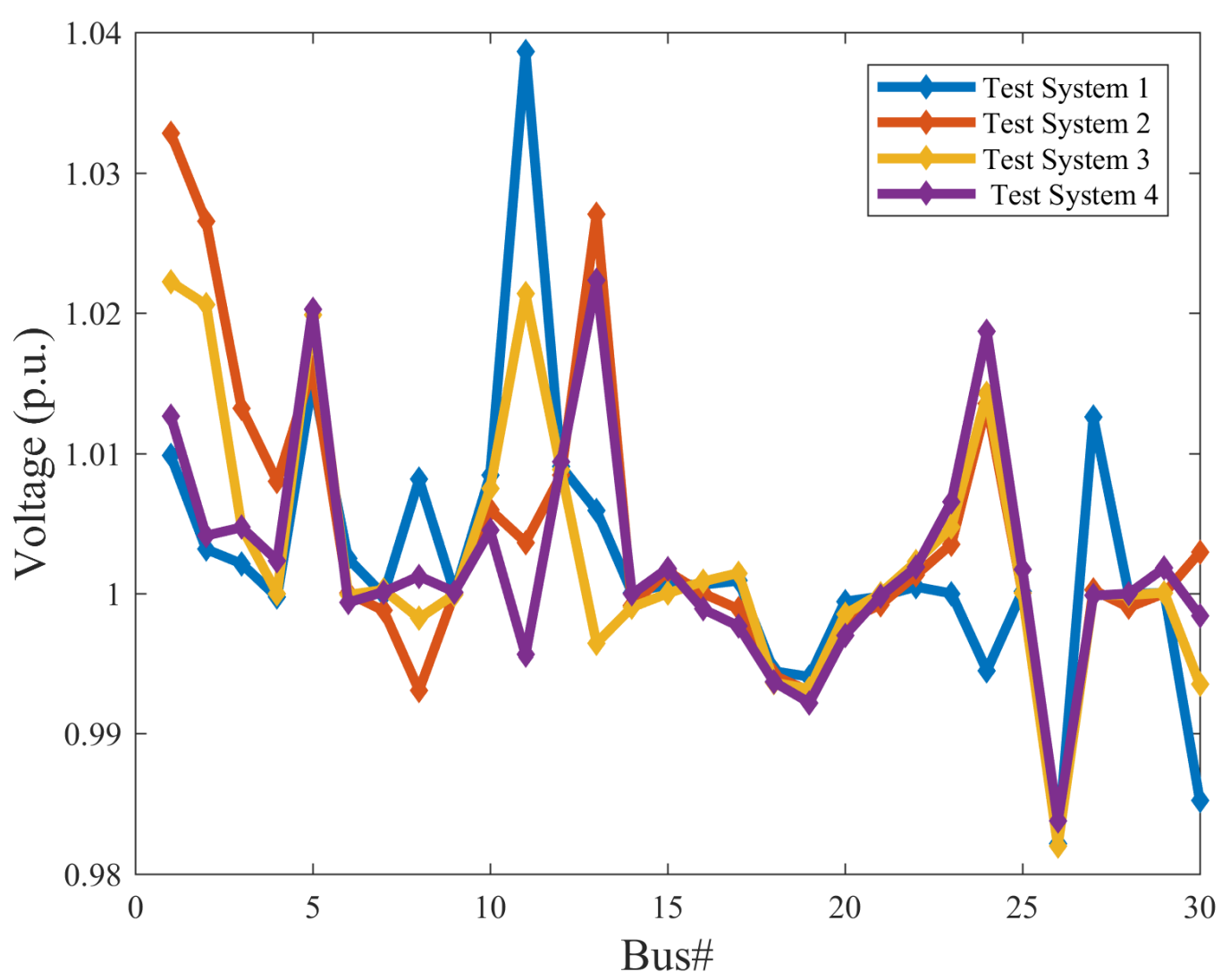

Figure 11. Voltage profiles of case 4 for all test systems using EO. 
Table 18. Optimal settings of control variables for case 4 for all test systems using EO.

\begin{tabular}{|c|c|c|c|c|c|c|}
\hline Parameters & Min & Max & Test system 1 & Test system 2 & Test system 3 & Test system 4 \\
\hline PG2 (MW) & 20 & 80 & 70.18121441 & 35.84850999 & 73.22346542 & 42.82238053 \\
\hline PG5 (MW) & 15 & 50 & 25.52703119 & 20.27116158 & 33.56379457 & 47.02961201 \\
\hline PG8 (MW) & 10 & 35 & 28.87890546 & 17.61889372 & 18.04097353 & 33.85695266 \\
\hline PG11 (MW) & 10 & 30 & 29.30401557 & 24.63092203 & 10.13966121 & 14.67013887 \\
\hline PG13 (MW) & 10 & 40 & 27.92172576 & 15.28698582 & 21.57955174 & 39.93831108 \\
\hline PG24 (MW) & 10 & 30 & & 16.34156919 & 10.07569951 & 28.44997135 \\
\hline PG30 (MW) & 10 & 40 & & 26.43024961 & 24.9797807 & 28.73744876 \\
\hline V1 (p.u.) & 0.95 & 1.1 & 1.009811989 & 1.032801388 & 1.022207169 & 1.012647301 \\
\hline V2 (p.u.) & 0.95 & 1.1 & 1.0031535 & 1.026505843 & 1.020581934 & 1.004121334 \\
\hline V5 (p.u.) & 0.95 & 1.1 & 1.015213206 & 1.016105476 & 1.019877057 & 1.020275353 \\
\hline V8 (p.u.) & 0.95 & 1.1 & 1.008124785 & 0.993094249 & 0.998231049 & 1.001227396 \\
\hline V11 (p.u.) & 0.95 & 1.1 & 1.038640051 & 1.003641057 & 1.02134836 & 0.99563608 \\
\hline V13 (p.u.) & 0.95 & 1.1 & 1.005894818 & 1.02703208 & 0.996453698 & 1.022325949 \\
\hline V24 (p.u.) & 0.95 & 1.1 & & 1.013528762 & 1.014235434 & 1.018656779 \\
\hline V30 (p.u.) & 0.95 & 1.1 & & 1.002929877 & 0.993533496 & 0.998414844 \\
\hline QC10 (MVAr) & 0 & 5 & 4.9994342 & 1.057601365 & 4.449085771 & 1.224696754 \\
\hline QC12 (MVAr) & 0 & 5 & 4.602398118 & 2.55410853 & 4.99999823 & 2.663316679 \\
\hline QC15 (MVAr) & 0 & 5 & 4.960424711 & 4.999607248 & 1.610176653 & 3.415934203 \\
\hline QC17 (MVAr) & 0 & 5 & 0.01181544 & 0.217347144 & 1.996228043 & 0.019033266 \\
\hline QC20 (MVAr) & 0 & 5 & 4.996883927 & 4.92956648 & 4.978309396 & 4.994054795 \\
\hline QC21 (MVAr) & 0 & 5 & 4.956429831 & 1.646590977 & 0.034134918 & 4.819904248 \\
\hline QC23 (MVAr) & 0 & 5 & 4.972309922 & 0.427048793 & 1.956957345 & 1.039869954 \\
\hline QC24 (MVAr) & 0 & 5 & 4.980435681 & 2.406207968 & 4.614781826 & 0.613094925 \\
\hline QC29 (MVAr) & 0 & 5 & 2.520824595 & 1.71349761 & 3.890942901 & 3.740081954 \\
\hline T11 (p.u.) & 0.9 & 1.1 & 1.056 & 1.01 & 1681 & 1.002332018 \\
\hline T12 (p.u.) & 0.9 & 1.1 & 0.901402975 & 0.900 & 5005 & 0.901 \\
\hline T15 (p.u.) & 0.9 & 1.1 & 0.981060937 & 1.013218403 & 0.960787866 & 0.998733169 \\
\hline T36 (p.u.) & 0.9 & 1.1 & 0.966944023 & 0.987755959 & 0.989855906 & 0.98143194 \\
\hline PG1 (MW) & 50 & 200 & 108.1160533 & 133.9296827 & 97.60688393 & 51.45175998 \\
\hline QG1 (MVAr) & -20 & 150 & -19.10239902 & -19.59757178 & -19.11821266 & -0.518817877 \\
\hline QG2 (MVAr) & -20 & 60 & -14.85253038 & 31.85856685 & 18.90601653 & -16.64972076 \\
\hline QG5 (MVAr) & -15 & 62.5 & 57.49581183 & 49.60698522 & 51.42002978 & 56.50571855 \\
\hline QG8 (MVAr) & -15 & 48 & 45.23093447 & 11.80532985 & 26.14354452 & 31.44056819 \\
\hline QG11 (MVAr) & -10 & 40 & 20.12674964 & 2.380585374 & 10.62092072 & -1.914317997 \\
\hline QG13 (MVAr) & -15 & 44 & -1.74441538 & 13.80317636 & -8.465359993 & 10.55389137 \\
\hline QG24 (MVAr) & -15 & 44 & & 14.86630972 & 15.99035449 & 13.88576475 \\
\hline QG 30 (MVAr) & -15 & 44 & & -4.888937122 & -7.68659143 & -7.960636408 \\
\hline$V D$ (p.u.) & & & 0.088397534 & 0.08005165 & 0.064632335 & 0.07266919 \\
\hline$F C(\$ / \mathbf{h})$ & & & 848.7795548 & 480.1984844 & 514.2584395 & 339.455916 \\
\hline$P_{\text {loss }}(\mathbf{M W})$ & & & 6.528945889 & 6.957974748 & 5.809810669 & 3.556575273 \\
\hline$E($ ton$/ h)$ & & & 0.240505607 & 0.155665569 & 0.119726864 & 0.091393798 \\
\hline$T C(\$ / \mathbf{h})$ & & & & 787.9483007 & 810.1863986 & 861.8303756 \\
\hline$C_{T}^{W}(\mathbf{\$} / \mathbf{h})$ & & & & 164.040337 & & 522.3744597 \\
\hline$C_{T}^{P V}(\mathbf{\$} / \mathbf{h})$ & & & & 143.7094792 & 295.9279591 & \\
\hline$f_{o}$ (p.u.) & & & 0.088397534 & 0.08005165 & 0.064632335 & 0.07266919 \\
\hline
\end{tabular}

It is clear from Table 19; the minimum best, standard deviation, and median are obtained by the EO. 
Table 19. Summary of the statistical analysis of case 4 for test system 1 .

\begin{tabular}{ccccc}
\hline & Best & Worst & Mean & Std dev \\
\hline MFO & 0.100862 & 0.137899 & 0.117452 & 0.011555 \\
TACPSO & 0.092725 & 0.177792 & 0.116202 & 0.025827 \\
AGPSO1 & 0.102816 & 0.144276 & 0.131944 & 0.01565 \\
TLBO & 0.103244 & 0.152343 & 0.112717 & 0.015185 \\
EO & 0.088398 & 0.097568 & 0.092814 & 0.002809 \\
MPSO & 0.093414 & 0.202628 & 0.124612 & 0.038641 \\
\hline
\end{tabular}

From Fig.12, the voltage and loading profiles for this case for all optimization methods obey the constraints of voltages at load buses and transmission line loading. It can be also observed that the EO convergence characteristic outperforms the convergence characteristics of other methods. The results of EO and other methods for test system 1 are given in Table 20 .

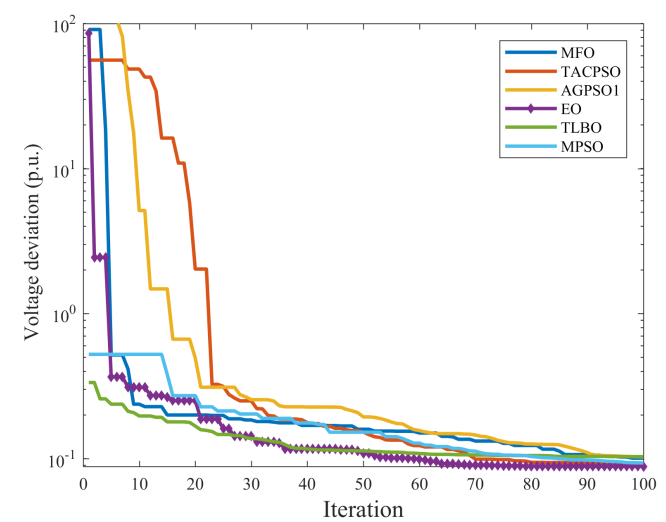

(a) Comparative convergence curves.

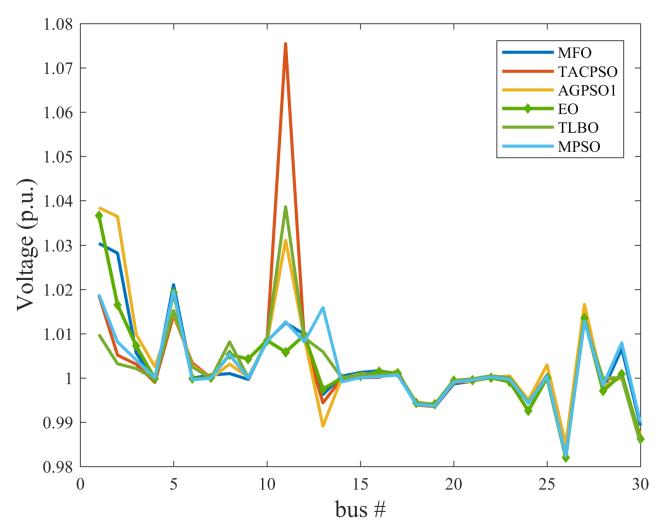

(b) Voltage profile.

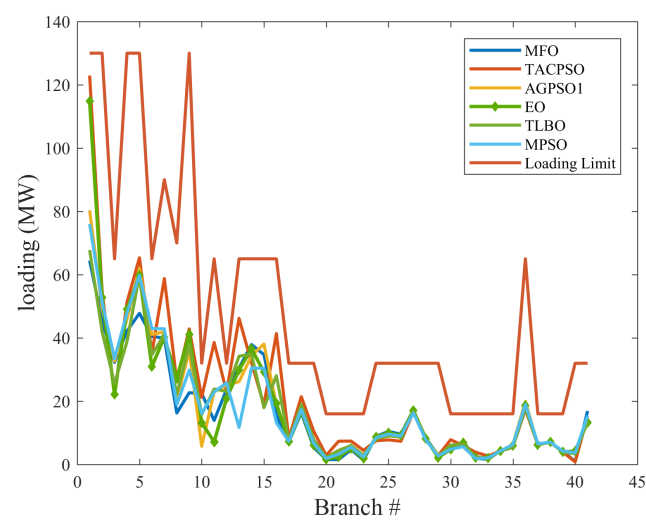

(c) Loading Profile

Figure 12. Comparative convergence, voltage and loading profiles for case 4 for all test systems. 
Table 20. Results of EO and other methods of case 4 for test system 1.

\begin{tabular}{ccccccc}
\hline & MFO & TACPSO & AGPSO1 & TLBO & EO & MPSO \\
\hline$V D$ (p.u.) & 0.100862 & 0.092725 & 0.102816 & 0.103243696 & 0.088398 & 0.093414 \\
$F C(\$ / \mathrm{h})$ & 901.7397 & 852.0642 & 834.1079 & 829.5879108 & 848.7796 & 841.3429 \\
$P_{\text {loss }}(\mathrm{MW})$ & 5.965677 & 9.980964 & 7.492151 & 8.391654887 & 6.528946 & 7.564352 \\
$E$ (ton/h) & 0.248497 & 0.359732 & 0.273799 & 0.337325958 & 0.240506 & 0.275282 \\
\hline$f_{o}$ (p.u.) & 0.100862 & 0.092725 & 0.102816 & 0.103243696 & 0.088398 & 0.093414 \\
\hline
\end{tabular}

6.2.5. Case 5: Minimization of the total cost of the generating units, voltage deviation, real power loss, and emission index

It is clear from Fig.13, the EO has the best convergence characteristics compared to the other optimization algorithms and the voltage and loading profiles for all algorithms ranges within the allowable limits. The results of EO and other methods for test system 1 of this case are shown in Table 21.

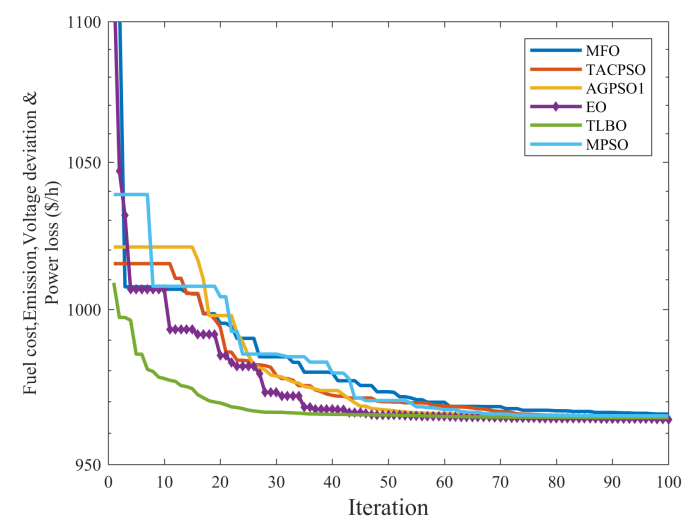

(a) Comparative convergence curves.

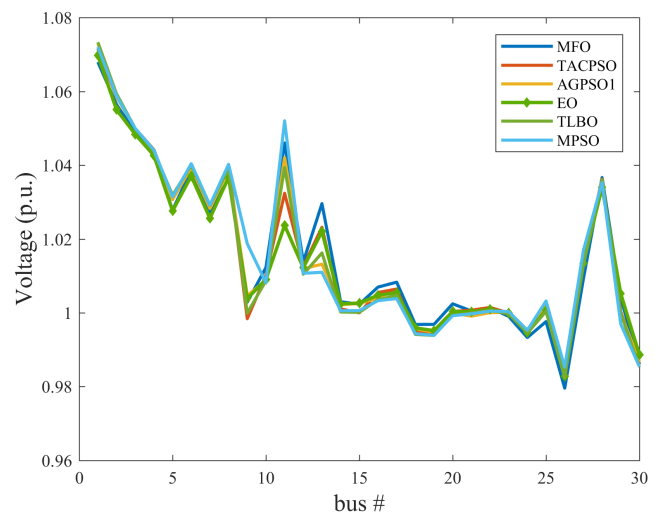

(b) Voltage profile.

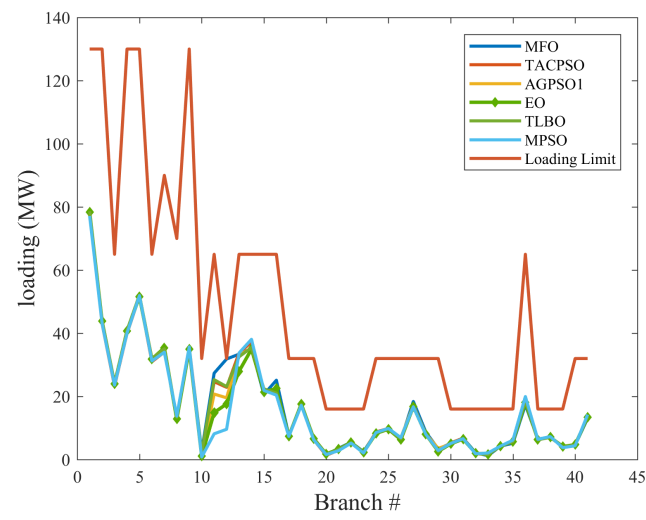

(c) Loading profile.

Figure 13. Comparative convergence, voltage and loading profiles for case 5 for all test system 1 . 
Table 21. Results of EO and other methods of case 5 for test system 1.

\begin{tabular}{ccccccc}
\hline & MFO & TACPSO & AGPSO1 & TLBO & EO & MPSO \\
\hline$V D($ p.u. $)$ & 0.312222 & 0.301092 & 0.2979 & 0.292001838 & 0.291525 & 0.315655 \\
$F C(\$ / \mathrm{h})$ & 832.131 & 833.4427 & 831.8455 & 831.251448 & 829.9924 & 833.2358 \\
$P_{\text {loss }}(\mathrm{MW})$ & 5.569804 & 5.471244 & 5.542919 & 5.575077257 & 5.604236 & 5.490564 \\
$E($ ton $/ \mathrm{h})$ & 0.250434 & 0.249973 & 0.251339 & 0.252691258 & 0.253454 & 0.249919 \\
\hline$f_{o}(\$ / \mathrm{h})$ & 965.9816 & 964.8825 & 964.8211 & 964.8363202 & 964.2232 & 965.4054 \\
\hline
\end{tabular}

The statistical analysis of the EO and other methods for test system 1 are given in Table 22. As shown in table, the EO gives the minimum best, median and standard deviation.

Table 22. Summary of the statistical analysis of case 5 for test system 1.

\begin{tabular}{ccccc}
\hline & Best & Worst & Mean & Std dev \\
\hline MFO & 965.9816 & 970.7178 & 968.0071 & 1.616872 \\
TACPSO & 964.8825 & 968.5757 & 965.8415 & 1.251791 \\
AGPSO1 & 964.8211 & 967.8093 & 965.6185 & 0.874411 \\
TLBO & 964.8363 & 968.0825 & 966.0087 & 1.105687 \\
EO & 964.2232 & 966.3464 & 964.5618 & 0.655197 \\
MPSO & 965.4054 & 978.9642 & 966.4455 & 4.054598 \\
\hline
\end{tabular}

It is clear from Fig.14 and Table 23 that the objective function for this case for test system 2, test system 3, and test system 4 dropped by $3.90 \%, 7.77 \%$, and $7.84 \%$, respectively compared to test system 1 . It is found from Table 23 that the real power loss for test system 2, test system 3, and test system 4 dropped by 30.94\%, 20.75\%, and $46.06 \%$, respectively compared to test system 1 . 


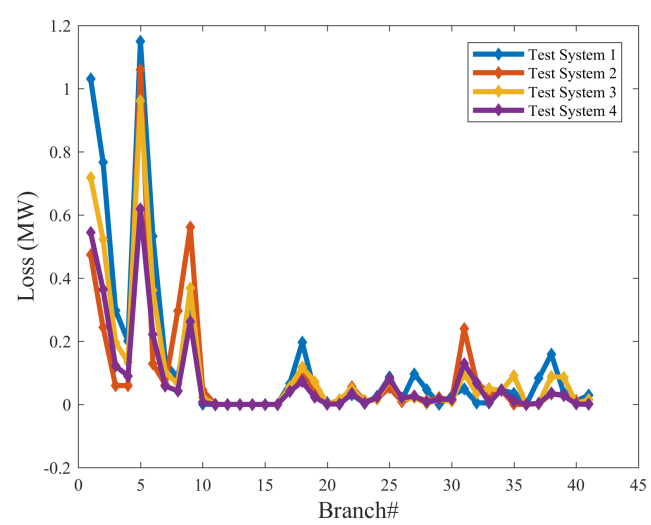

(a) Loss profile.

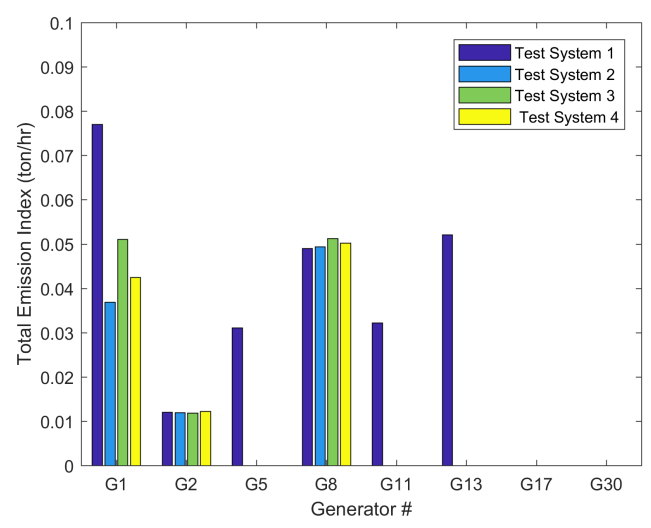

(c) Total emission index.

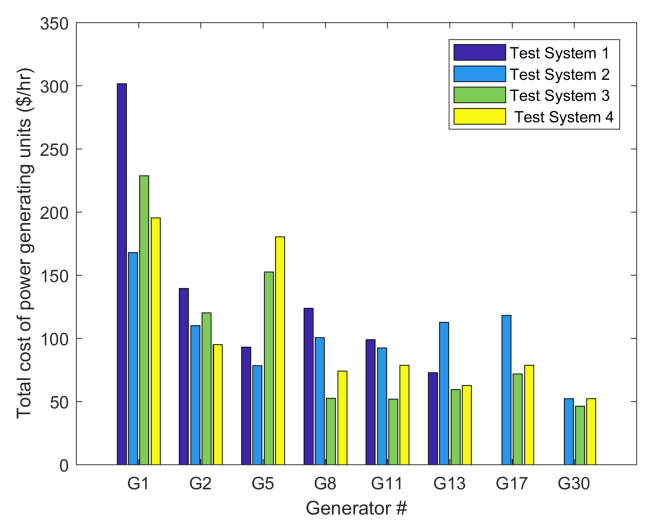

(b) Total cost of generating units.

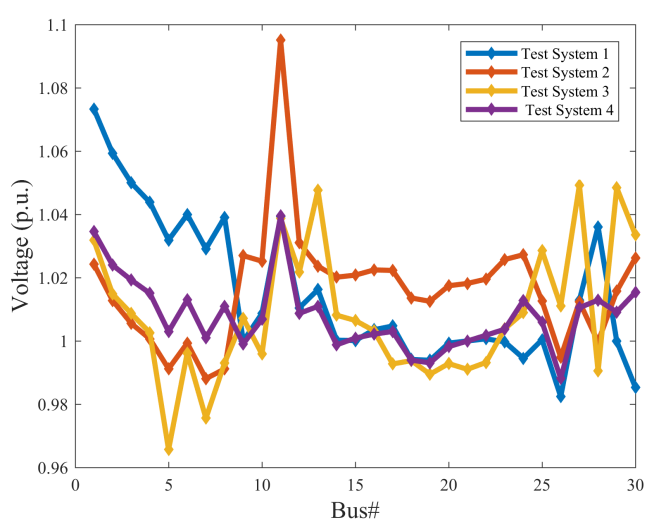

(d) Voltage profiles.

Figure 14. Total cost of generating units, total emission index, voltage and loss profiles of case 5 for all test systems. 
Table 23. Optimal settings of control variables for case 5 for all test systems using EO.

\begin{tabular}{|c|c|c|c|c|c|c|}
\hline Parameters & Min & Max & Test system 1 & Test system 2 & Test system 3 & Test system 4 \\
\hline PG2 (MW) & 20 & 80 & 52.34900301 & 43.76198174 & 46.85392201 & 39.04580002 \\
\hline PG5 (MW) & 15 & 50 & 31.41892625 & 25.13957863 & 41.57764325 & 49.63341394 \\
\hline PG8 (MW) & 10 & 35 & 34.99720302 & 28.83722988 & 15.57308058 & 21.63539649 \\
\hline PG11 (MW) & 10 & 30 & 26.95716205 & 27.72005416 & 28.54767347 & 26.5299306 \\
\hline PG13 (MW) & 10 & 40 & 20.69034077 & 37.30220041 & 21.35593529 & 20.93782021 \\
\hline PG24 (MW) & 10 & 30 & & 33.41823981 & 19.87429698 & 27.03669094 \\
\hline PG30 (MW) & 10 & 40 & & 17.31391519 & 17.29441758 & 17.27175615 \\
\hline V1 (p.u.) & 0.95 & 1.1 & 1.073302714 & 1.024270078 & 1.031881955 & 1.034535652 \\
\hline V2 (p.u.) & 0.95 & 1.1 & 1.05933056 & 1.012773005 & 1.014838234 & 1.023955028 \\
\hline V5 (p.u.) & 0.95 & 1.1 & 1.031867076 & 0.991186486 & 0.965629646 & 1.002922115 \\
\hline V8 (p.u.) & 0.95 & 1.1 & 1.039079245 & 0.991138879 & 0.993005954 & 1.010973253 \\
\hline V11 (p.u.) & 0.95 & 1.1 & 1.039336016 & 1.1 & 1.038730973 & 1.039568814 \\
\hline V13 (p.u.) & 0.95 & 1.1 & 1.016224258 & 1.023619922 & 1.047631647 & 1.010922024 \\
\hline V24 (p.u.) & 0.95 & 1.1 & & 1.027240201 & 1.008908379 & 1.012804196 \\
\hline V30 (p.u.) & 0.95 & 1.1 & & 1.026258901 & 1.033487159 & 59168 \\
\hline QC10 (MVAr) & 0 & 5 & 1.42704702 & 0.24222794 & 5 & 3.367347878 \\
\hline QC12 (MVAr) & 0 & 5 & 0.114983911 & 4.465905221 & 5 & 4.957438998 \\
\hline QC15 (MVAr) & 0 & 5 & 2.71927269 & 0 & 1.436680682 & 3.38628092 \\
\hline QC17 (MVAr) & 0 & 5 & 4.777257639 & 4.971408287 & 0 & 4.999449612 \\
\hline QC20 & 0 & 5 & 4.891165116 & 4.864936873 & 5 & 4.836689278 \\
\hline QC21 (MVAr) & 0 & 5 & 4.917867343 & 4.114355205 & 4.252301174 & 2.729537609 \\
\hline QC23 ( & 0 & 5 & 4.944826897 & 4.912774176 & 0 & 1.224294666 \\
\hline QC24 (MVAr) & 0 & 5 & 4.999139393 & 3.383242169 & 2.790571405 & 4.901232863 \\
\hline QC29 (MVAr) & 0 & 5 & & 0.6226 & 5 & 0405 \\
\hline T11 (p.u.) & 0.9 & 1.1 & 1.098277898 & 1.041847001 & 0.996768732 & 1.070613035 \\
\hline T12 (p.u.) & 0.9 & 1.1 & 0.937769396 & 0.906411875 & 1.061448786 & 0.920185016 \\
\hline T15 (p.u.) & 0.9 & 1.1 & 1.02148431 & 0.939592837 & 0.983885511 & 0.995441894 \\
\hline T36 (p.u.) & 0.9 & 1.1 & 1.002153866 & 0.991006369 & 0.904079564 & 0.993400466 \\
\hline PG1 (MW) & 50 & 200 & 122.5915999 & & 96.76396309 & 6618 \\
\hline QG1 (MVAr) & -20 & 150 & 0.44760914 & 4.980415704 & 11.6826979 & -1.350997342 \\
\hline QG2 (MVAr) & -20 & 60 & 13.45186855 & 10.12960773 & 16.17020662 & 8.009356413 \\
\hline QG5 (MVAr) & -15 & 62.5 & 22.96436543 & 30.2545861 & -0.480850004 & 19.94798351 \\
\hline QG8 (MVAr) & -15 & 48 & 25.09929462 & 4.325252485 & 25.37843413 & 24.0097914 \\
\hline QG11 (MVAr) & -10 & 40 & 20.42841833 & 39.34377358 & 16.58858651 & 20.9433804 \\
\hline QG13 (MVAr) & -15 & 44 & 4.484753294 & -4.510415315 & 19.67801235 & 1.913484758 \\
\hline QG24 (MVAr) & -15 & 44 & & -1.505790029 & 2.129992746 & 2.949992903 \\
\hline QG 30 (MVAr) & -15 & 44 & & 3.138390036 & -7.584798837 & 0.645488754 \\
\hline$V D$ (p.u.) & & & 0.291524702 & 0.340717958 & 0.287869453 & 0.142747756 \\
\hline$F C(\$ / \mathbf{h})$ & & & 829.9923878 & 378.7198323 & 401.6872426 & 364.5623372 \\
\hline$P_{\text {loss }}(\mathbf{M W})$ & & & 5.604235892 & 3.870229887 & 4.440932453 & 3.022674546 \\
\hline$E($ ton$/ h)$ & & & 0.253453881 & 0.098214148 & 0.114249163 & 0.104949647 \\
\hline$T C(\$ / \mathbf{h})$ & & & & 832.9987095 & 783.916446 & 817.6301115 \\
\hline$C_{T}^{W}(\mathbf{\$} / \mathbf{h})$ & & & & 144.7990782 & & 453.0677743 \\
\hline$C_{T}^{P V}$ (\$/h) & & & & 309.4797989 & 382.2292034 & \\
\hline$f_{o}(\mathbf{\$} / \mathbf{h})$ & & & 964.2232199 & 927.1649129 & 889.8329526 & 889.1206976 \\
\hline
\end{tabular}

\section{Conclusions}

In this study, a novel proposed EO method has been successfully applied to solve single and multi-objective OPF with integrated wind turbines and solar PV generators. Its performance and effectiveness were evaluated on four power system, namely: IEEE 30-bus system, wind integrated IEEE 30-bus system, solar PV integrated IEEE 30-bus system, and hybrid wind and solar PV integrated IEEE 30-bus system. Realistic models for the wind turbines and solar PV systems have been proposed and thus real power outputs of wind turbines and solar PV power plants have been accurately forecasted.Therefore, correct and efficient decision can be taken for inclusion the wind turbines and solar PV power plants in the proper locations. The simulation and statistical results indicate 
and approve that the EO[35] method outperforms other optimization techniques ,namely: TLBO [45], MPSO [44], MFO [43], AGPSO1 [44], and TACPSO [44] .Our research has highlighted the importance of the proper locations of the renewable energy resources on improving the objective functions of OPF problem. Furthermore, adding wind turbines and solar PV play an integral role in enhancing the performance of the standard IEEE 30-bus system .For example, they significantly reduce the fuel cost and emission of the conventional power generators , as well as minimize real power loss and voltage deviation .

Author Contributions: Both authors have made equal contributions to this work.

Funding: This research received no external funding.

Conflicts of Interest: The authors declare no conflict of interest.

\section{References}

1. Roy, R.; Jadhav, H. Optimal power flow solution of power system incorporating stochastic wind power using Gbest guided artificial bee colony algorithm. International Journal of Electrical Power \& Energy Systems 2015, 64, 562-578.

2. Shi, L.; Wang, C.; Yao, L.; Ni, Y.; Bazargan, M. Optimal power flow solution incorporating wind power. IEEE Systems Journal 2011, 6, 233-241.

3. Biswas, P.P.; Suganthan, P.N.; Mallipeddi, R.; Amaratunga, G.A. Optimal reactive power dispatch with uncertainties in load demand and renewable energy sources adopting scenario-based approach. Applied Soft Computing 2019, 75, 616-632.

4. Biswas, P.P.; Suganthan, P.; Amaratunga, G.A. Optimal power flow solutions incorporating stochastic wind and solar power. Energy Conversion and Management 2017, 148, 1194-1207.

5. Dommel, H.; Tinney, W. 91968) Optimal Power Flow solutions IEEE Transactions on Power Apparatus and Systems, Vol. PAS-87 1866, 1876.

6. Jabr, R.A. Optimal power flow using an extended conic quadratic formulation. IEEE transactions on power systems 2008, 23, 1000-1008.

7. Lin, W.M.; Huang, C.H.; Zhan, T.S. A hybrid current-power optimal power flow technique. IEEE Transactions on Power Systems 2008, 23, 177-185.

8. Glavitsch, H.; Spoerry, M. Quadratic loss formula for reactive dispatch. IEEE transactions on power apparatus and systems 1983, pp. 3850-3858.

9. Burchett, R.; Happ, H.; Wirgau, K. Large scale optimal power flow. IEEE Transactions on Power Apparatus and Systems 1982, pp. 3722-3732.

10. Lobato, E.; Rouco, L.; Navarrete, M.; Casanova, R.; Lopez, G. An LP-based optimal power flow for transmission losses and generator reactive margins minimization. 2001 IEEE Porto Power Tech Proceedings (Cat. No. 01EX502). IEEE, 2001, Vol. 3, pp. 5-pp.

11. Duman, S.; Güvenç, U.; Sönmez, Y.; Yörükeren, N. Optimal power flow using gravitational search algorithm. Energy Conversion and Management 2012, 59, 86-95.

12. El Ela, A.A.; Abido, M.; Spea, S. Optimal power flow using differential evolution algorithm. Electric Power Systems Research 2010, 80, 878-885.

13. Bouchekara, H. Optimal power flow using black-hole-based optimization approach. Applied Soft Computing 2014, 24, 879-888.

14. Mohamed, A.A.A.; Mohamed, Y.S.; El-Gaafary, A.A.; Hemeida, A.M. Optimal power flow using moth swarm algorithm. Electric Power Systems Research 2017, 142, 190-206.

15. Hazra, J.; Sinha, A. A multi-objective optimal power flow using particle swarm optimization. European transactions on electrical power 2011, 21, 1028-1045.

16. Bhattacharya, A.; Roy, P. Solution of multi-objective optimal power flow using gravitational search algorithm. IET generation, transmission \& distribution 2012, 6, 751-763.

17. Shabanpour-Haghighi, A.; Seifi, A.R.; Niknam, T. A modified teaching-learning based optimization for multi-objective optimal power flow problem. Energy Conversion and Management 2014, 77, 597-607.

18. Kumar, S.; Chaturvedi, D. Optimal power flow solution using fuzzy evolutionary and swarm optimization. International Journal of Electrical Power \& Energy Systems 2013, 47, 416-423. 
19. Khorsandi, A.; Hosseinian, S.; Ghazanfari, A. Modified artificial bee colony algorithm based on fuzzy multi-objective technique for optimal power flow problem. Electric Power Systems Research 2013, 95, 206-213.

20. Ghasemi, M.; Ghavidel, S.; Ghanbarian, M.M.; Gharibzadeh, M.; Vahed, A.A. Multi-objective optimal power flow considering the cost, emission, voltage deviation and power losses using multi-objective modified imperialist competitive algorithm. Energy 2014, 78, 276-289.

21. Narimani, M.R.; Azizipanah-Abarghooee, R.; Zoghdar-Moghadam-Shahrekohne, B.; Gholami, K. A novel approach to multi-objective optimal power flow by a new hybrid optimization algorithm considering generator constraints and multi-fuel type. Energy 2013, 49, 119-136.

22. Ghasemi, M.; Ghavidel, S.; Akbari, E.; Vahed, A.A. Solving non-linear, non-smooth and non-convex optimal power flow problems using chaotic invasive weed optimization algorithms based on chaos. Energy 2014, 73, 340-353.

23. Krishnanand, K.; Hasani, S.M.F.; Panigrahi, B.K.; Panda, S.K. Optimal power flow solution using self-evolving brain-storming inclusive teaching-learning-based algorithm. International Conference in Swarm Intelligence. Springer, 2013.

24. Sivasubramani, S.; Swarup, K. Sequential quadratic programming based differential evolution algorithm for optimal power flow problem. IET generation, transmission \& distribution 2011, 5, 1149-1154.

25. Reddy, S.S. Optimal power flow with renewable energy resources including storage. Electrical Engineering 2017, 99, 685-695.

26. Shilaja, C.; Arunprasath, T. Optimal power flow using Moth Swarm Algorithm with Gravitational Search Algorithm considering wind power. Future Generation Computer Systems 2019, 98, 708-715.

27. Aien, M.; Fotuhi-Firuzabad, M.; Rashidinejad, M. Probabilistic optimal power flow in correlated hybrid wind-photovoltaic power systems. IEEE Transactions on Smart Grid 2014, 5, 130-138.

28. Aien, M.; Rashidinejad, M.; Firuz-Abad, M.F. Probabilistic optimal power flow in correlated hybrid wind-PV power systems: A review and a new approach. Renewable and Sustainable Energy Reviews 2015, 41, 1437-1446.

29. Liang, R.H.; Tsai, S.R.; Chen, Y.T.; Tseng, W.T. Optimal power flow by a fuzzy based hybrid particle swarm optimization approach. Electric Power Systems Research 2011, 81, 1466-1474.

30. Shilaja, C.; Ravi, K. Optimal power flow using hybrid DA-APSO algorithm in renewable energy resources. Energy Procedia 2017, 117, 1085-1092.

31. Biswas, P.P.; Suganthan, P.; Amaratunga, G.A. Optimal power flow solutions incorporating stochastic wind and solar power. Energy Conversion and Management 2017, 148, 1194-1207.

32. Das, T.; Roy, R.; Mandal, K.K.; Mondal, S.; Mondal, S.; Hait, P.; Das, M.K. Optimal Reactive Power Dispatch Incorporating Solar Power Using Jaya Algorithm. In Computational Advancement in Communication Circuits and Systems; Springer, 2020; pp. 37-48.

33. Chen, M.R.; Zeng, G.Q.; Lu, K.D. Constrained multi-objective population extremal optimization based economic-emission dispatch incorporating renewable energy resources. Renewable Energy 2019, 143, 277-294.

34. Rambabu, M.; Nagesh Kumar, G.; Sivanagaraju, S. Optimal Power Flow of Integrated Renewable Energy System using a Thyristor Controlled SeriesCompensator and a Grey-Wolf Algorithm. Energies 2019, 12, 2215.

35. Faramarzi, A.; Heidarinejad, M.; Stephens, B.; Mirjalili, S. Equilibrium optimizer: A novel optimization algorithm. Knowledge-Based Systems 2019, p. 105190.

36. Biswas, P.P.; Suganthan, P.N.; Mallipeddi, R.; Amaratunga, G.A. Optimal power flow solutions using differential evolution algorithm integrated with effective constraint handling techniques. Engineering Applications of Artificial Intelligence 2018, 68, 81-100.

37. Shaheen, A.M.; El-Sehiemy, R.A.; Farrag, S.M. Solving multi-objective optimal power flow problem via forced initialised differential evolution algorithm. IET Generation, Transmission \& Distribution 2016, 10, 1634-1647.

38. Panda, A.; Tripathy, M. Security constrained optimal power flow solution of wind-thermal generation system using modified bacteria foraging algorithm. Energy 2015, 93, 816-827.

39. Shargh, S.; Mohammadi-Ivatloo, B.; Seyedi, H.; Abapour, M.; others. Probabilistic multi-objective optimal power flow considering correlated wind power and load uncertainties. Renewable Energy 2016, 94, 10-21.

40. Biswas, P.P.; Suganthan, P.N.; Qu, B.Y.; Amaratunga, G.A. Multiobjective economic-environmental power dispatch with stochastic wind-solar-small hydro power. Energy 2018, 150, 1039-1057.

41. Hu, F.; Hughes, K.J.; Ma, L.; Pourkashanian, M. Combined economic and emission dispatch considering conventional and wind power generating units. International Transactions on Electrical Energy Systems 2017, 27, e2424. 
42. Hu, F.; Hughes, K.J.; Ingham, D.B.; Ma, L.; Pourkashanian, M. Dynamic economic and emission dispatch model considering wind power under Energy Market Reform: A case study. International Journal of Electrical Power \& Energy Systems 2019, 110, 184-196.

43. Mirjalili, S. aMFOMoth-flame optimization algorithm: A novel nature-inspired heuristic paradigm. Knowledge-Based Systems 2015, 89, 228-249.

44. Mirjalili, S.; Lewis, A.; Sadiq, A.S. Autonomous particles groups for particle swarm optimization. Arabian Journal for Science and Engineering 2014, 39, 4683-4697.

45. Rao, R.V.; Savsani, V.J.; Vakharia, D. aTLBOTeaching-learning-based optimization: an optimization method for continuous non-linear large scale problems. Information sciences 2012, 183, 1-15.

46. Taha, I.B.; Elattar, E.E. Optimal reactive power resources sizing for power system operations enhancement based on improved grey wolf optimiser. IET Generation, Transmission \& Distribution 2018, 12, 3421-3434.

47. Alsac, O.; Stott, B. Optimal load flow with steady-state security. IEEE transactions on power apparatus and systems 1974.

48. Zimmerman, R.D.; Murillo-Sánchez, C.E.; Gan, D. MATPOWER: A MATLAB power system simulation package. Manual, Power Systems Engineering Research Center, Ithaca NY 1997, 1. 